\title{
SYNTHESIS OF NITROGEN-CONTAINING COMPOUNDS FROM HIGHER TERPENOIDS
}

\author{
Aculina Aricu \\ Institute of Chemistry of the Academy of Sciences of Moldova, Chişinău, \\ MD-2028, Academiei str. 3, Republic of Moldova \\ E-mail: aricu_aculina@yahoo.com; Phone: +7 (373 2) 739963; Fax: +7 (373 2) 739775
}

Dedicated to Academician Pavel Vlad on his 75-th birthday

\begin{abstract}
The presence of nitrogen in the molecule is usually accompanied either by the appearance of a new activity or the intensification of original activity characteristic for the native terpenoids. This maintains alive the scientific interest in the synthesis of such compounds. The present communication put into discussion the recently elaborated methods for preparation of the nitrogen-containing terpenic compounds.
\end{abstract}

Keywords: synthesis, nitrogen-containing compounds, terpenoids, Beckmann rearrangement.

\section{Introduction}

Many terpenes exhibit various biological activities [1, 2]. In a series of articles it has been reported on the appearance of a new activity or the intensification of the original activity that accompanies the introduction of nitrogen in the molecules of native terpenoids. Therefore the synthesis of the nitrogen-containing terpenic compounds is of great interest for further studies of their biological activity.

\section{Synthesis of the nitrogenated derivatives of drimanes and homodrimanes}

The nitrogen-containing sesquiterpenic compounds and their biological activity represent a poorly studied area of terpenoid chemistry. The first synthesis of the homodrimanic nitrogen derivatives was reported by Grant $\mathrm{P}$. K. et al. in 1983 [3]. Oxidative degradation of manool (1) [4] gives the intramolecular acetals (2) and (3). The former possesses a powerful ambra-type odour and is being used in the perfumery industry. In this light it was interesting to examine the synthesis of the nitrogen analogues (4) and (5). Reaction of the methylene ketone (6), in turn obtained from the permanganate oxidation of manool (1), with hydroxylamine gave the isomeric oximes (7) and (8) in 5:2 ratio. Their stereochemistry was assigned on the basis of the corresponding amides obtained under Beckmann rearrangement conditions. By direct treating of the oximes with thionyl chloride only low yields of amides were obtained, while by using the base-promoted rearrangement of the tosylate derivatives the yields were greatly increased.<smiles>C=C[C@](C)(O)CC[C@H]1C(=C)CC[C@H]2[C@@H](C)CCC[C@]12C</smiles>

1

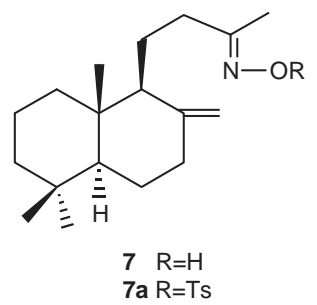<smiles>[X]C1(C)CC[C@@H]2[C@](O)(CC[C@]3(C)C(C)(C)CCC[C@]23C)O1</smiles>

$2 \mathrm{X}=\mathrm{Me}$ $4 \mathrm{X}=\mathrm{NHMe}$<smiles>[R]O/N=C(/C)CC[C@@H]1C(=C)CC[C@H]2C(C)(C)CCC[C@@]21C</smiles>

$8 \mathrm{R}=\mathrm{H}$ 8a $R=T s$<smiles>[X]C12CC[C@@H]3C(C)(C)CCC[C@@]3(C)[C@@]3(CC[C@@]1(C)O3)O2</smiles>

$3 \mathrm{X}=\mathrm{Me}$ $5 \mathrm{X}=\mathrm{NHMe}$<smiles>C=C1CC[C@H]2[C@@H](C)CCC[C@]2(C)[C@H]1CCNC(C)=O</smiles><smiles>[X]C(C)CC[C@H]1C(=C)CC[C@H]2[C@@H](C)CCC[C@]12C</smiles>

6<smiles>C=C1CC[C@H]2[C@@H](C)CCC[C@]2(C)[C@H]1CCC(=O)NC</smiles>

10

Scheme 1

The tosyl derivative (7a) of the less polar oxime (7) furnished the amide (9) in quantitative yield upon treatment with dilute base at room temperature. Since it is known, that Beckmann rearrangement proceeds by a stereospecific antimigration, the E-configuration for the oxime (7) has been established. The more polar (O-tosyl) oxime (8a) required 
more forcing conditions to effect the rearrangement and gave the amide (10) in $27 \%$ yield. Since the amide structure was established to be as depicted in formula (10), this pointed to Z-stereochemistry of the parent oxime (8). The rearrangement of the oxime tosylates under acidic conditions gave the same amide product (9), thus reflecting the facile isomerization of the less stable Z- (O-tosyl)oxime (8a) prior to rearrangement [5].

Later the synthesis was reported by Urones, J.G. et al. [6] describing the use of 12-acetoxy-7,9(11)-drimandien (11), that was in turn prepared from methyl zamoranate (12), as a precursor for C-9 nitrogenated drimanes (Scheme 2). Dien (11) reacts with m-CPBA in a regio- and stereoselective way, affording the epoxide mixture of compounds (13) and (14) [7]. On ulterior derivatisation the $\alpha$-epoxide afforded carbonates (15) and (17) and carbamates (16) and (18). A1 kaline hydrolysis of acetate (18) by using a $2 \mathrm{~N} \mathrm{NaOH}$ solution in dioxan (1/1) afforded the corresponding alcohol (19) in $96 \%$ yield [8]. Extreme reaction conditions, including saturated solution of $\mathrm{KOH}$ and 1,2-ethanediol at $70^{\circ} \mathrm{C}$ [9] led to the difficultly isolable amino diol (20) in $90 \%$ yield. Its treatment with $\mathrm{Ac}_{2} \mathrm{O} / \mathrm{Py}$ [10] gave the spirodihydrooxazole acetate (21) in $84 \%$ yield. In virtue of the amino alcohol high reactivity, the protection of its amino group was required. Hence (21) was treated with (Boc) ${ }_{2} \mathrm{O}$ [11], yielding the N-Boc derivative (22) in $73 \%$ yield. Since the latter was resistant to hydrolysis, it could be reduced with DIBAL-H, furnishing diol (23) in good yield (73\%).

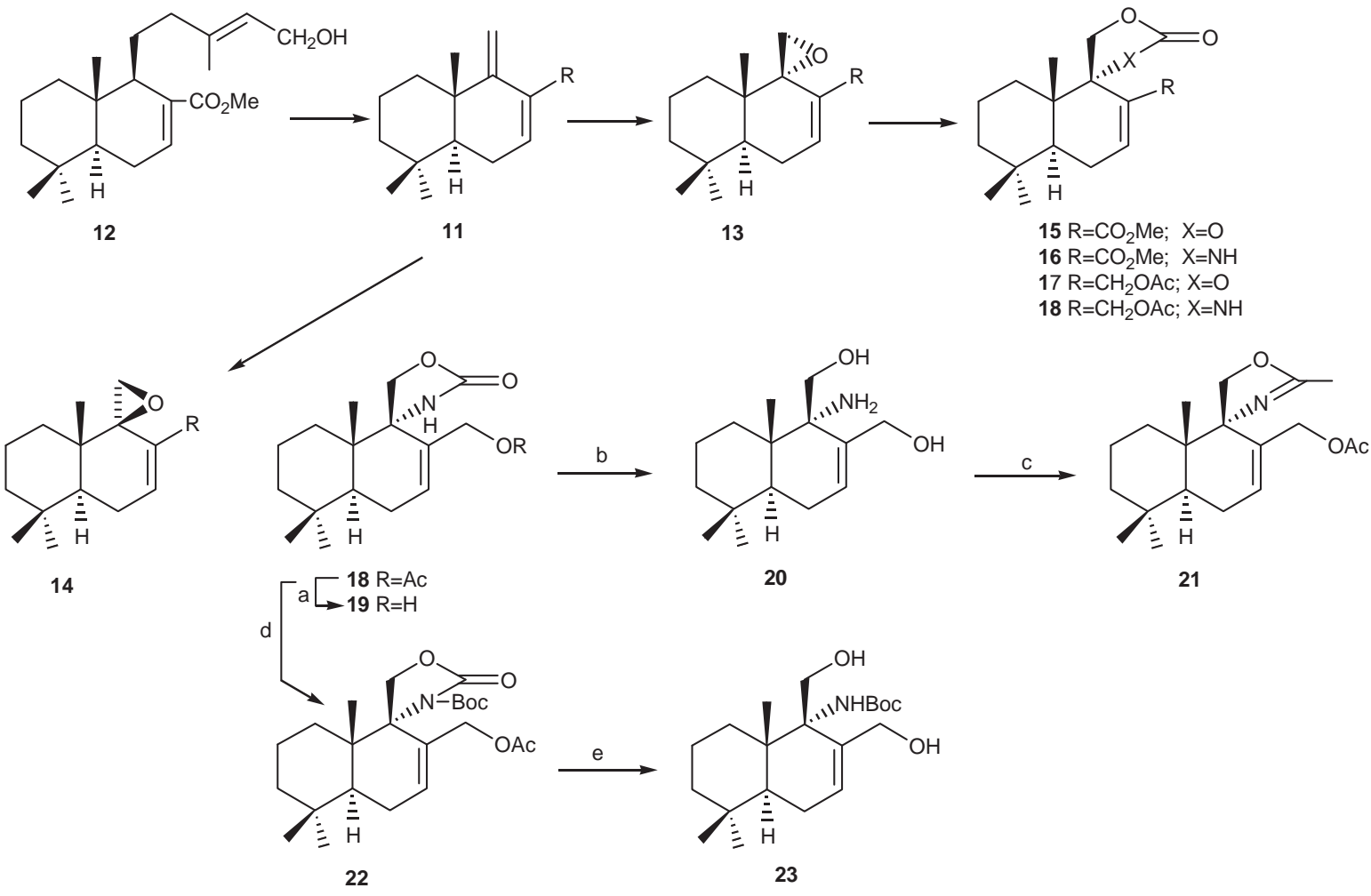

Reagents: a) aqueous $2 \mathrm{~N} \mathrm{NaOH} / 1,4$-dioxane $1 / 1,96 \%$; b) saturated $\mathrm{KOH}$ in $\mathrm{H}_{2} \mathrm{O}, 1$, 2-etanediol, $70^{\circ} \mathrm{C}, 90 \%$; c) $\mathrm{Ac}_{2} \mathrm{O}, \mathrm{Py}, 84 \%$; d) (Boc) ${ }_{2} \mathrm{O}, \mathrm{Et}_{3} \mathrm{~N}$, DMAP, THF, $73 \%$; e) DIBAL-H, $\mathrm{CH}_{2} \mathrm{Cl}_{2},-78^{\circ} \mathrm{C}, 73 \%$.

\section{Scheme 2}

New synthetic strategies to prepare natural drimanes from (-)-sclareol (24) have been reported by Barrero and co-workers [12]. Thus the preparation of natural 9,11-drimen-8 $\alpha$-ol (25) through the nitrogen-containing compounds is described. Synthesis of compound (25) started with the homodrimanic acid (26), in turn obtained from sclareol (24) in $75 \%$ overall yield by a two-step sequence [13]. The Curtius rearrangement of the acyl azide derived from (26) represented the key-step in the discussed synthesis. Treatment of (26) with diphenylphosphorylazide (DPPA) in the presence of triethylamine with subsequent reflux in benzene gave the isocyanate (27) [14]. All attempts to transform the latter into the corresponding amine were unsuccessful: hydrolysis of the isocyanate afforded only a very stable cyclic carbamate. Therefore the way was chosen to reduce compound (27) till the formamide (28) that was next treated with potassium hydroxide in methanol to afford the hydroxyacetamide (29) or the aminoalcohol (30), respectively, depending upon the reaction temperature. Then, the transformation of amine (30) into (25) was approached. First of all, diazotization of the amine group was attempted. The main observations were that the amine (30) remained unaltered when it was treated at $0{ }^{\circ} \mathrm{C}$ with sodium nitrite and hydrochloric acid, while at room temperature its decomposition occurred. Hofmann elimination turned out to be also unsuccessful. Treatment of alcohol (30) with potassium tertbutoxide in dimethylsulfoxide after exhaustive methylation afforded the methoxyamine (31). In this way the hydroxyl group of compound (28) was protected by treating it with ethyl vinyl ether to give (32). Saponification of the latter 
consistently afforded the amine (33), which underwent elimination after exhaustive methylation on treatment under basic conditions yielding (34). The removal of protection subsequently gave (25) (Scheme 3).<smiles>C=C[C@](C)(O)CC[C@@H]1[C@@](C)(O)CC[C@H]2C(C)(C)CCC[C@]21C</smiles>

24<smiles>CCO[C@@]1(C)CC[C@H]2[C@@H](C)CCC[C@]2(C)[C@H]1CN</smiles>

33

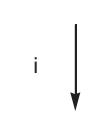<smiles>C=C1[C@]2(O)C(C)(C)CCC[C@@]2(C)CC[C@@]1(C)O</smiles>

j $\longrightarrow \begin{aligned} & 34 \mathrm{R}=\mathrm{EE} \\ & 25 \mathrm{R}=\mathrm{H}\end{aligned}$

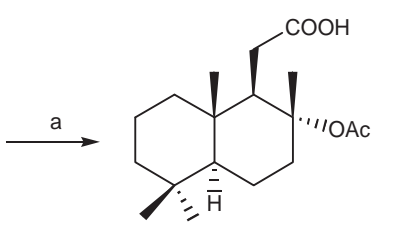

26<smiles>CCO[C@@]1(C)CC[C@H]2C(C)(C)CCC[C@]2(C)[C@@H]1CNC(C)=O</smiles>

32<smiles>CC(=O)O[C@]1(C)CC[C@@H]2C(C)(C)CCC[C@@]2(C)[C@@H](CN=O)C1(C)C</smiles>

27<smiles></smiles>

d $\longrightarrow \begin{aligned} & 28 \mathrm{R}=\mathrm{H} ; \mathrm{R}^{1}=\mathrm{Ac} \\ & 29 \mathrm{R}=\mathrm{Me} ; \mathrm{R}^{1}=\mathrm{H}\end{aligned}$<smiles>[R20]C[C@@H]1[C@@](C)(O)CC[C@]2(C)[C@@](C)(O)CCC[C@]12C</smiles>

f $\begin{aligned} & 30 \mathrm{R}, \mathrm{R}^{1}=\mathrm{H} \\ & \\ & \mathbf{3 1} \mathrm{R}, \mathrm{R}^{1}=\mathrm{Me}\end{aligned}$

Reagents: a) 1. $\mathrm{OsO}_{4}, \mathrm{NaIO}_{4}$, t-BuOH, $45^{\circ} \mathrm{C}, 6 \mathrm{~h}$.; 2 . Jones' oxidation, acetone, $0^{\circ} \mathrm{C}, 45 \mathrm{~min}$ ( $75 \%$ overall yield); b) 1. DPPA (1.1 eq), $\mathrm{Et}_{3} \mathrm{~N}$ (1.1 eq), Dioxan, $0^{\circ} \mathrm{C}, 1.5 \mathrm{~h} ; 2$. Benzene, reflux; c) $\mathrm{NaBH}_{4}(3 \mathrm{eq}), \mathrm{EtOH}, 0^{\circ} \mathrm{C}, 30$ min. (80\%); d) KOH, MeOH, rt, 6 h (96\%); e) KOH, MeOH, reflux, 12 h (95\%); f) 1. Excess MeI, t-BuOMe; 2. t-BuOK (1.4 eq), DMSO ( $80 \%$ ); g) ethyl vinyl ether (8 eq), CSA (0.5 eq), $\mathrm{CH}_{2} \mathrm{Cl}_{2}, \mathrm{rt}, 25 \mathrm{~h} \mathrm{(75 \% );} \mathrm{h)} \mathrm{KOH}$, $\mathrm{MeOH}$, reflux, 2 h (91\%); i)1. excess MeI, t-BuOMe; 2. t-BuOK (2.7 eq), DMSO (85\%); j) AcOH, MeOH, rt, $2 \mathrm{~h}(95 \%)$.

\section{Scheme 3}

Many drimane sesquiterpenoids, including their prototype drimenol (35), exibit various biological activities.<smiles>CC1=CCC2C(C)(C)CCC[C@]2(C)[C@H]1CO</smiles>

35<smiles>CC1=CC[C@H]2[C@@H](C)CCC[C@]2(C)[C@H]1C</smiles>

39<smiles>CC1=CC[C@H]2C(C)(C)CCC[C@]2(C)[C@H]1C=O</smiles>

37<smiles>CC1=CC[C@H]2[C@@H](C)CCC[C@]2(C)[C@H]1CN</smiles>

36

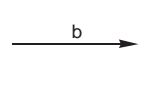<smiles>CC1CC[C@H]2C(C)(C)CCC[C@]2(C)[C@H]1CN</smiles>

40

Reagents: a) $\mathrm{P}_{2} \mathrm{O}_{5}$, DMSO, $20^{\circ} \mathrm{C}, 95 \%$; b) $\mathrm{NH}_{2} \mathrm{OH} \cdot \mathrm{HCl}$; EtOH, $\mathrm{Py}, 95 \%$; c) $\mathrm{Ac}_{2} \mathrm{O}, \mathrm{Py}, 64 \%$; d) p-TsCl, $\mathrm{Py}$, $90 \%$; e) $\mathrm{LiAlH}_{4}, \mathrm{AlCl}_{3}, \mathrm{Et}_{2} \mathrm{O}, 50 \%$; f) $\mathrm{NaBH}_{4}, \mathrm{CoCl}_{2} \cdot \mathrm{H}_{2} \mathrm{O}, \mathrm{MeOH}, 20^{\circ} \mathrm{C}, 91 \%$.

\section{Scheme 4}

Therefore, it seemed interesting to synthesize the amino- analog of drimenol in order to study its biological properties. We accomplished the synthesis of 11-aminodrim-7-ene (36) from drimenol (35) in four steps [15] (Scheme 4). Drimenol (35) was oxidized into drimenal (37) in 95\% yield via phosphoric anhydride activated dimethylsulfoxide, 
as previously reported [16]. Drimenal oxime (38) was obtained on interaction of drimenal (37) with hydroxylamine hydrochloride in the ethanol-pyridine mixture of solvents. According to TLC, the reaction product consisted of a mixture of $Z$ - and $E$-isomers. The oxime of 14,15-bisnorlabd-8-(17)-en-13-one (7) was used as reference to show that the less polar isomer had the $E$-configuration [3]. Since the $E$-configuration of (7) is energetically more favourable, the predominant isomer in the mixture should most probably be the $E$-isomer. In the drimenal oxime (38) obtained by us the above-mentioned less polar isomer predominated. Its content in the mixture after recrystallization from hexane was $80 \%$, the ratio of $Z$ - and $E$-isomers being approximately 1:4. Next we investigated the production of drimenylamine (36) via the reduction of drimenal oxime (38) by various methods [17-20]. Compound (36) could not be synthesized in satisfactory yield by the reduction of drimenal oxime (38), that is why we decided to convert (38) into the corresponding nitrile (39) and then reduce it to the amine (36). Several methods have been employed by us in order to synthesize (39) [21-27]. As a result, we found as acceptable methods for synthesizing (39) the reactions of (38) with $p$ - $\mathrm{TsCl}_{\mathrm{or}} \mathrm{Ac} \mathrm{O}_{2} \mathrm{O}$ in pyridine. The target- product, 11-aminodrim-7-ene (36), was obtained in 50\% yield by refluxing the hydroxylamine (38) with $\mathrm{LiAlH}_{4}$ in $\mathrm{Et}_{2} \mathrm{O}$ in the presence of anhydrous $\mathrm{AlCl}_{3}$ [28].

The reduction of nitrile (39) by $\mathrm{NaBH}_{4}, \mathrm{CoCl}_{2} \cdot 6 \mathrm{H}_{2} \mathrm{O}$ in $\mathrm{CH}_{3} \mathrm{OH}$ produced compounds (36) and 7,8-dihydro-11aminodrimane (40), as a mixture of water-soluble hydrochlorides. The ${ }^{1} \mathrm{H}$ NMR-spectrum of the mixture indicated on a $2: 1$ ratio of the hydrochlorides of (36) and (40). The pure compound (36) and its mixture with (40), synthesized by us, are of interest as potentially endowed with biological activity.

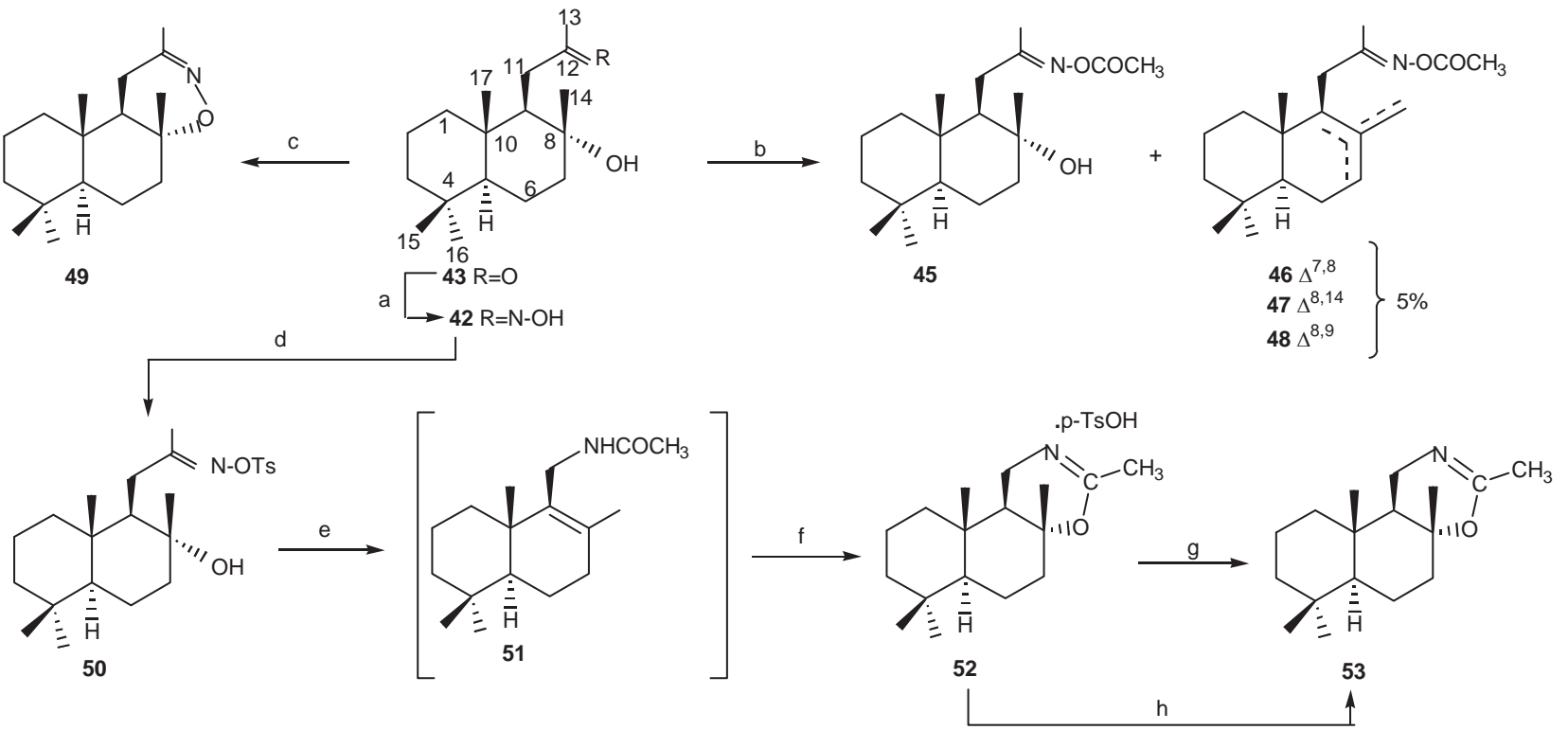<smiles>CC(=O)NC[C@@H]1[C@@](C)(O)CC[C@@H]2[C@]1(C)CCC[C@@]2(C)O</smiles><smiles>CC1(C)CCC[C@@]2(C)[C@H]1CC[C@@]1(C)OC(=O)C[C@H]21</smiles>

Reagents: a) $\mathrm{NH}_{2} \mathrm{OH} \cdot \mathrm{HCl}$, EtOH, Py; b) $\mathrm{Ac}_{2} \mathrm{O} / \mathrm{Py}, 105-110^{\circ} \mathrm{C}$; c) $86 \% \mathrm{H}_{3} \mathrm{PO}_{4}, 60-70{ }^{\circ} \mathrm{C}, 82 \%$; d) p-TsCl, $\mathrm{Py}$, $90 \%$; e) $\mathrm{CH}_{3} \mathrm{CN}, \Delta$; f) p-TsON, $95 \%$; g) $10 \% \mathrm{KOH}, \mathrm{MeOH}, 95 \%$; h) $\mathrm{Al}_{2} \mathrm{O}_{3}, 58 \%$.

\section{Scheme 5}

The synthesis of amide (41) via Beckmann rearrangement of oxime (42) of 11-dihomodriman-8 $\alpha$-ol-12-one (43) was the main our goal we pursued [29]. Hydroxyketone (43) is readily available, being obtained from norambreinolide (44) by the method described by us [30]. Oxime (42) was prepared from compound (43) by its reaction with $\mathrm{NH}_{2} \mathrm{OH} \cdot \mathrm{HCl}$ in an ethanol-pyridine mixture of solvents. Compound (42) represented a mixture of $Z$ - and $E$-isomers, according to its TLC data and ${ }^{1} \mathrm{H},{ }^{13} \mathrm{C}$, and ${ }^{15} \mathrm{~N}$ NMR spectra. In virtue of easy conversion of $Z$ - into the $E$-isomer as a result of the fact that the latter is energetically more favorable [3], we used (42) for the reactions as a mixture of its $Z$ - and $E$-isomers. It was found that on interaction of the oxime (42) with acetic anhydride în pyridine the oxime acetate (45) along with a small amount of the mixture of isomeric dehydrated oxime acetates (46)-(48) were formed. On heating of the solution of the oxime (42) in $86 \% \mathrm{H}_{3} \mathrm{PO}_{4}$ the elimination of water occurred giving 1,2-oxazine (49). Oxime (42) interacts with $p$-tosyl chloride in pyridine affording the oxime tosylate (50). The latter rearranges under reflux in acetonitrile, according to the 
Beckmann transpozition, with the elimination of the water and $p$-toluene sulfonic acid, giving the unsaturated amide (51). The reaction of compound (51) with p-TsOH leads to the corresponding salt of cyclic 1,3-oxazine (52) formation, which upon treatment with a metanolic solution of potassium hydroxide furnished compound (53).

The new nitrogen containing drimanic compounds, the 1,2,6-oxazine and N-pyroline oxide derivatives were obtained [31], which are of interest as compounds potentially endowed with interesting biological properties. 11-dihomodriman-8 $\alpha$-ol-12-one (43) was prepared according to the reported protocol [30] and subjected to the dehydration in the presence of the „Amberlist-15” ionite. As result ketone (54) was obtained, which was transformed into oxime (55) by interaction with $\mathrm{NH}_{2} \mathrm{OH} \cdot \mathrm{HCl}$.<smiles>CC(=O)C[C@@H]1[C@@](C)(O)CC[C@H]2C(C)(C)CCC[C@@]21C</smiles>

43

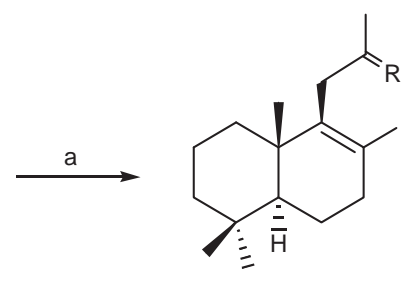

$\mathrm{b} \longrightarrow \begin{aligned} & 54 \mathrm{R}=\mathrm{O} \\ & 55 \mathrm{R}=\mathrm{NOH}\end{aligned}$

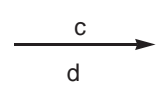

Reagents: a) Amberlist-15, $\mathrm{CH}_{2} \mathrm{Cl}_{2}, 20^{\circ} \mathrm{C}, 20 \mathrm{~h}, 70 \%$; $(64: 65)=36 \%: 56 \% ; \mathrm{CF}_{3} \mathrm{CO}_{2} \mathrm{H},(64: 65)=30 \%: 48 \%$.<smiles>CC1=NO[C@]2(C)CC[C@H]3C(C)(C)CCC[C@]3(C)[C@H]2C1</smiles>

56
57

\section{Scheme 6}

By heating at $70-80^{\circ} \mathrm{C}$ a solution of the oxime (55) in $86 \% \mathrm{H}_{3} \mathrm{PO}_{4}$, the intramolecular cyclization occurred, giving the mixture of $(1 \mathrm{~S}, 2 \mathrm{~S}, 4 \mathrm{aS}, 8 \mathrm{aS})-2,5,5,8 \mathrm{a}$-tetrametildecahidro-1H-nafto[1,2][5,6]-3-metil-4,5-dihidro-[1,2,6]oxazine (56) and (1S,2S,4aS,8aS)-2,5,5,8a-tetrametildecahidro-1H-nafto[1,2-d]-2-metilpirolin-N-oxide (57). The same outcome was reached by heating the oxime (55) in $\mathrm{CF}_{3} \mathrm{CO}_{2} \mathrm{H}$.

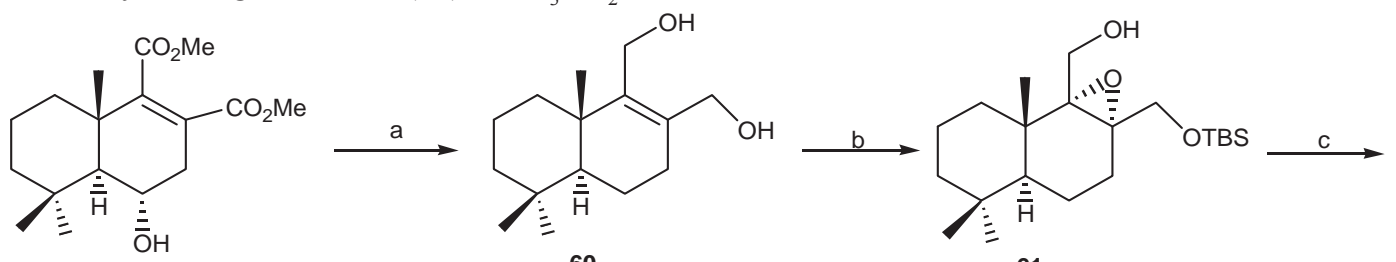

59

60

61<smiles>CO/C=C\[C@]1(O)[C@@H](CO[Sb])CC[C@H]2[C@@H](C)CCC[C@]21C</smiles>

62

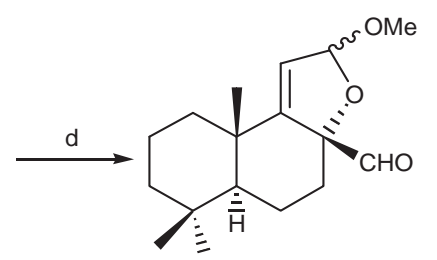

63

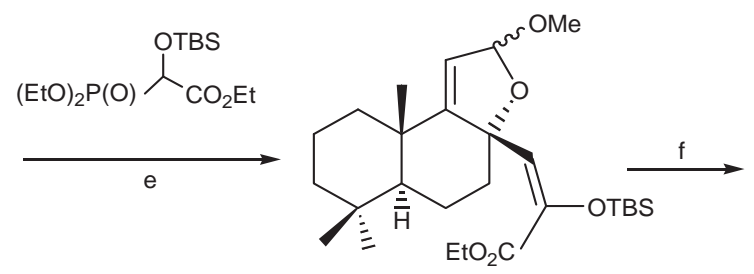

64<smiles>CC(C)[O+]=S</smiles>

Reagents: a) 1. CTDI, $\mathrm{CH}_{2} \mathrm{Cl}_{2}$, reflux, $21 \mathrm{~h},(94 \%), 2 . \mathrm{n}-\mathrm{Bu}_{3} \mathrm{SnH}, \mathrm{AIBN}$, toluene $80^{\circ} \mathrm{C}, 15 \mathrm{~min}$ (quant), 3. DIBAL, THF, $0^{\circ} \mathrm{C}, 15 \mathrm{~min}(98 \%)$; b) 1 . TBSCl, imidazole, DMF, $0^{\circ} \mathrm{C}$ to rt, $15 \mathrm{~min}(97 \%), 2 . \mathrm{MCPBA}_{2} \mathrm{CH}_{2} \mathrm{Cl}_{2}$, $0^{\circ} \mathrm{C}, 24 \mathrm{~h},(\alpha: 62 \%, \beta: 30 \%)$; c) 1. TPAP, NMO, $\mathrm{CH}_{2} \mathrm{Cl}_{2}, \mathrm{rt}, 3,5 \mathrm{~h}, 2$. $\mathrm{Ph}_{3} \mathrm{P}^{+} \mathrm{CH}_{2} \mathrm{OMeCl}^{-}, \mathrm{n}-\mathrm{BuLi} \mathrm{THF}, 0^{\circ} \mathrm{C}, 10$ $\min \left(60 \%\right.$ in two steps); d) 1 . TBAF, THF, $0^{\circ} \mathrm{C}$ to rt, $3 \mathrm{~h}(86 \%)$, 2. Dess-Martin periodinan $\left.\mathrm{CH}_{2} \mathrm{Cl}_{2}, \mathrm{rt}, 4 \mathrm{~h} ; \mathrm{e}\right)$ n-BuLi, THF, $0^{\circ} \mathrm{C}$ to rt, $1 \mathrm{~h}(48 \%$ in two steps $\alpha: \beta=4: 1)$; f) $\mathrm{MeLi}$, THF, $0^{\circ} \mathrm{C}, 10 \mathrm{~min}(72 \%, \mathrm{E}: \mathrm{Z}=4: 1)$; g) $\mathrm{NH}_{3}$, cat. AcOH, t-BuOH, rt, overnight [65\% from (E), 60\% from (Z)]; h) TBAF, THF, rt, 1,5 h, (89\%).

\section{Scheme 7}


A total synthesis of $( \pm$ ) chamobtusin A (58) has been accomplished [32] on the basis of presumed biosynthetic pathway, involving first the imine formation of keto-aldehyde followed then by intramolecular aza-Michael addition. The known alcohol (59) has been selected as a suitable starting material. Its hydroxyl group was converted into thiocarbamate which was then deoxygenated via the treatment with $n-\mathrm{Bu}_{3} \mathrm{SnH}$ and $\mathrm{AIBN}$, and the resulting diester was reduced with DIBAL to give diol (60) in high yield. The less hindered primary alcohol of (60) was selectively protected as the tertbutyldimethylsilyl ether. $m$-CPBA oxidation of the double bond gave a mixture of $\alpha$-and $\beta$-epoxides in a ratio of $2: 1$, and the major R-epoxide (61) was used in the next reaction. After tetra- $n$ - propylammonium perruthenate (TPAP) oxidation of the primary hydroxy group of (61), Wittig reaction of the resulting aldehyde under the conditions depicted in scheme 7 afforded enol ether (62) with the only Z-isomer of the double bond. The tert-butyldimethylsilyl-protection of compound (62) was removed with tetrabutylammonium fluoride (TBAF), and the liberated primary alcohol was oxidized with Dess-Martin periodinane to give the cyclic product (63). Horner-Wadsworth-Emmons reaction of compound (63) with phosphonate gave compound (64) as a mixture of $\alpha$ - and $\beta$ - isomers in a 4:1 ratio. It was possible to directly convert it into the cyclization precursor (64) by treatment with methyl lithium. Subsequent ring-opening of methyl acetal gave the desired keto-aldehyde (65) as a $E / Z$ mixture (cca $4: 1$ ratio) in $72 \%$ yield. As expected, the imine formation and subsequent intramolecular aza-Michael addition smoothly proceeded with both geometrical isomers of (66) by treatment with ammonia in the presence of catalytic amounts of acetic acid to afford compound (66) as a single diastereomer in $65 \%$ and $60 \%$ yield, correspondingly, for $E$ - and $Z$-isomer. Finally, the removal of the tert-butyldimethylsilyl group gave $( \pm$ )-chamobtusin A (58). The overall yield of (58) starting from (59) constituted 5.3\% in 13 steps.

\section{Synthesis of nitrogen-containing compounds from lambertianic acid}

During the last decades, the vast series of natural terpenoids has been intensely supplemented by metabolites of plant, microbial and animal origin, whose molecules include various structural fragments attached to the main terpene skeleton through covalent bonds. The unique structure of many so-called mixed metabolites and their important biological activities make them attractive targets of the total synthesis. On the other hand they can serve as plausible models for the design of molecules with useful properties. Among such metabolites, the nitrogen-containing and alkaloid-like compounds continuously attract the scientific interest.

The authors [33] describe a convenient approach to $\beta$-carboline diterpenoids as potential models of such metabolites, which is based on the Pictet- Spengler reaction.<smiles>[R]c1occc1CC[C@H]1C(=C)CC[C@H]2[C@@H](C)C(C)(C)CCC[C@]12C</smiles>

Reagents: a) 1) triptamine, 2) $\mathrm{NaBH}_{4}$; b) $\mathrm{CH}_{2} \mathrm{O}$, TsOH.

\section{Scheme 8}

Reductive amination of methyl 16-formyllambertianate (67) or its aldehyde (68) with tryptamine, in the presence of sodium borohydride gives amine (69) in $87 \%$ yield. The Pictet-Spengler cyclization of the resulting diterpenoindole amine with formaldehyde furnishes methyl 16-(1,2,3,4-tetrahydro- $\beta$-carbolin-2-yl-methyl)lambertianate (70). The reaction of formyl-substituted methyl labdatrienoates and labdadienoates with 2-(3-indolyl)ethylamines provides a convenient approach to 1 -diterpeno- $\beta$-carbolines.

The Diels-Alder reaction of lambertianic acid (71) with maleic anhydride occurred in a stereoselective fashion and yielded the diastereoisomeric $(1 R, 2 S, 6 R, 7 R)$ - and $(1 S, 2 R, 6 S, 7 S)$-exo-adducts (72a) and (72b) [34]. The latter reacted with $\mathrm{L}$-valinol in toluene in the presence of triethylamine to give the corresponding diterpenoid imides, 4-aza-9oxabicyclo[2.2.1] dec-8-enes (73a) and (73b). The product was a mixture of two diastereoisomers whose ratio (according to the ${ }^{1} \mathrm{H}$ NMR data of the mixture) was the same as the $(1 R, 2 S, 6 R, 7 R) /(1 S, 2 R, 6 S, 7 S)$ ratio in the initial adduct.

Reactions of lambertianic acid (71) with N-substituted maleinimides (74) in the presence of Lewis acids afforded diastereoisomeric adducts having both exo- and endo- configuration. With the aim of studying the effect of 
the N-substituent in the dienophile on the reaction stereoselectivity and biological activity of new nitrogen containing heterocycles of the terpene series, apart from $N$-benzylmaleimide, on synthesized compounds (75-78) with various substituents on the nitrogen. Some transformations of the adducts were examined with a view to obtain cantharidin and dihydroisoindole analogs.

Diels-Alder reaction of lambertianic acid (71) with cyclic dienophiles provides a convenient route to terpenoid cantharidin analogs. The nature of the dienophile is determinant for the stereochemistry of the addition. The reaction of lambertianic acid (71) with maleic anhydride yields exclusively the corresponding exo adducts, whereas with $\mathrm{N}$-substituted maleimides both endo and exo adducts are formed, whose ratio depends on the substituent on the nitrogen. In all the cases, diastereoisomeric pairs were obtained. The obtained products can serve as useful intermediates in the synthesis of diterpenoid analogs of the isoindole and benzophthalimide series.

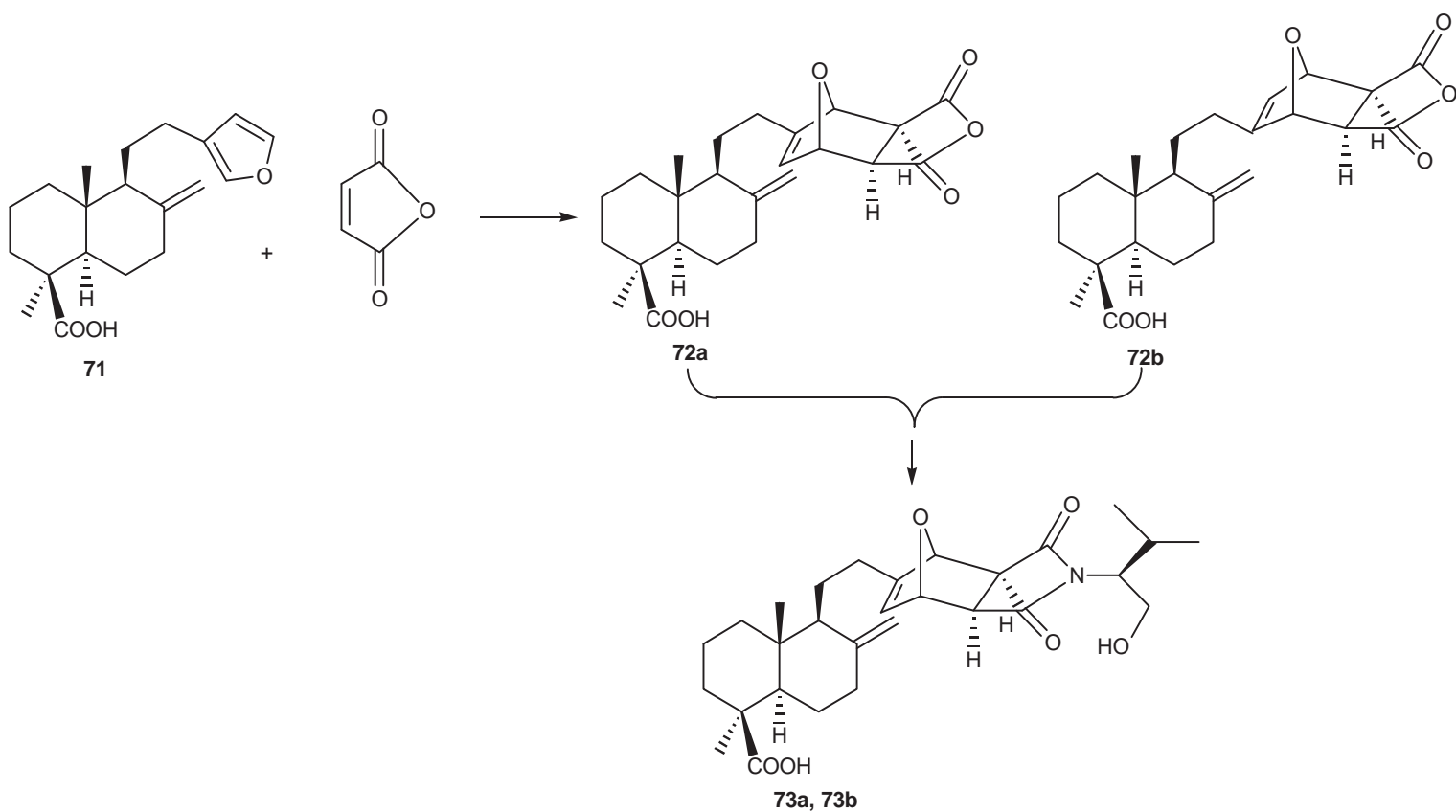

(71) +

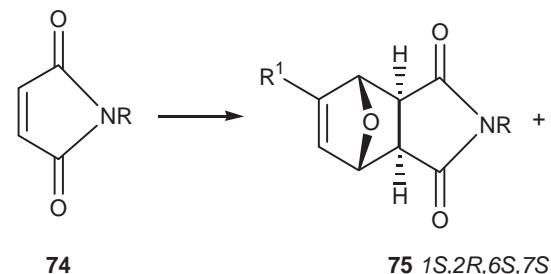<smiles>[R]C1=C[C@@H]2O[C@H]1[C@@H]1C(=O)NC(=O)[C@H]21</smiles>

$761 R, 2 S, 6 R, 7 R$

Scheme 9<smiles>[R7]C1=C[C@@H]2O[C@@H]1[C@H]1C(=O)NC(=O)[C@@H]21</smiles>

$771 S, 2 S, 6 R, 7 S$<smiles>[R]C1=C[C@@H]2O[C@H]1[C@H]1C(=O)NC(=O)[C@@H]21</smiles>

$781 R, 2 R, 6 S 7 R$

Heterocyclic derivatives of lambertianic acid were synthesized [35] via the reductive amination of carbonyl compounds and subsequent Mannich intramolecular aminomethylation. Treatment of ketone (79) with methylaminesodum borohydride afforded the mixture of 17-nor-8 $\alpha$-methylamino labdanoid (80) and secondary alcohol (81) in $52 \%$ and $33 \%$ yield, respectively (Scheme 10). Methylamino derivative (80) reacted with formaldehyde to give hexahydrofuroazocine (82). By the oxidation of 8,12-epoxy-17-hydroxy labdanoid (83) with pyridinium chlorochromate in methylene chloride on obtained the aldehyde (84) that after the reductive amination with methylamine-sodum borohydride gave the amine (85). As aforementioned for (80), the intramolecular aminomethylation of (85) by the action of formaldehyde smoothly led to formation of furoazonine (86). Under analogous conditions, the oxidation of 8-hydroxymethyl labdanoid (87) yielded a mixture of $(8 R)$ - and $(8 S)$ - aldehydes (88) at a ratio of 2:1. The subsequent reductive amination of (88) with tryptamine or phenylalanine methyl ester and sodium tetrahydridoborate resulted in the formation of the corresponding amines (89) and (90) as mixtures of stereoisomers. Furoazonine derivatives (91) and (92) have been obtained by cyclization in the presence of formaldehyde. Thus on proposed efficient methods for the synthesis of optically active heteropolycyclic compounds, namely furoazocine and furoazonine derivatives, via transformations of lambertianic acid methyl ester. 

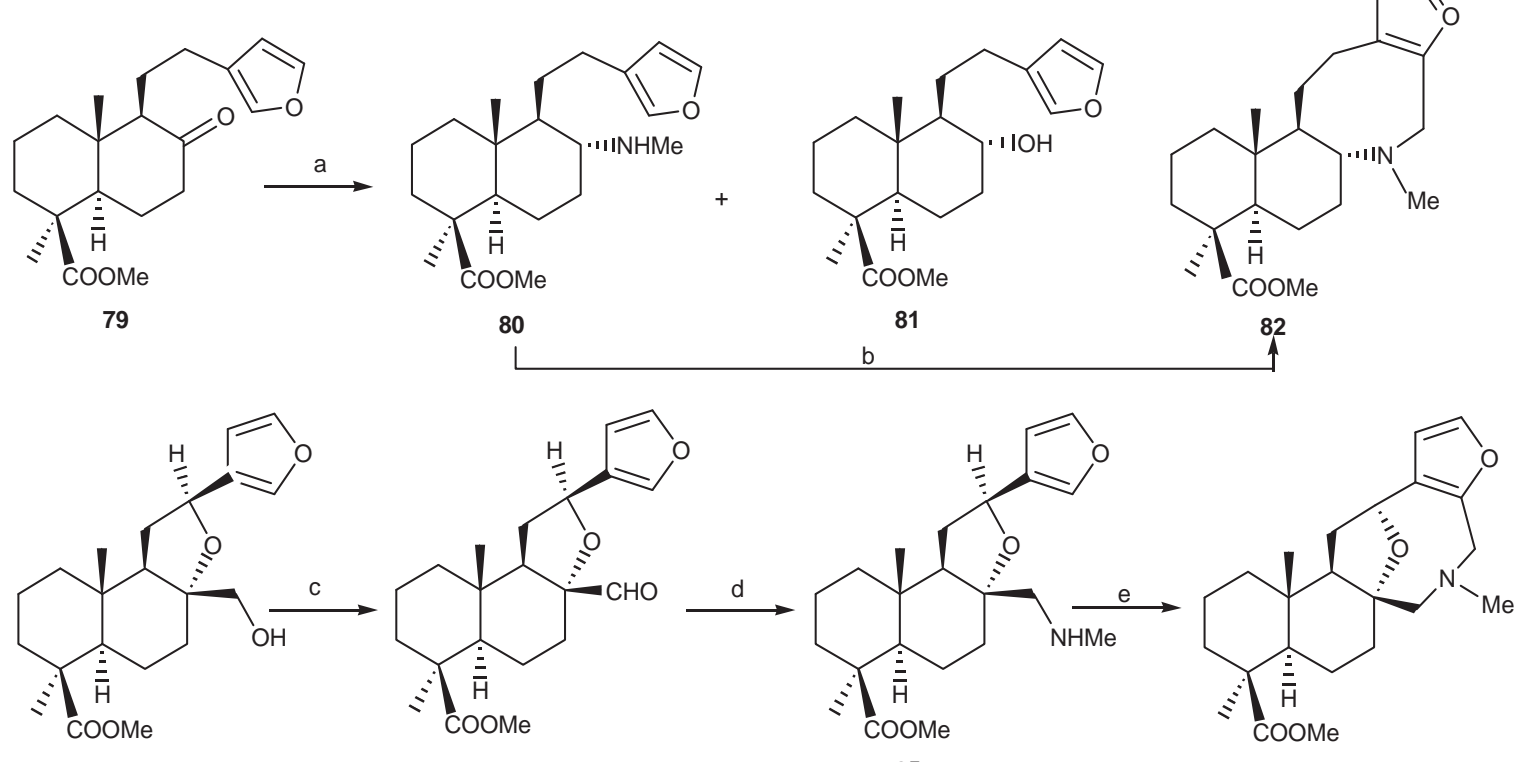

83

84

85

86

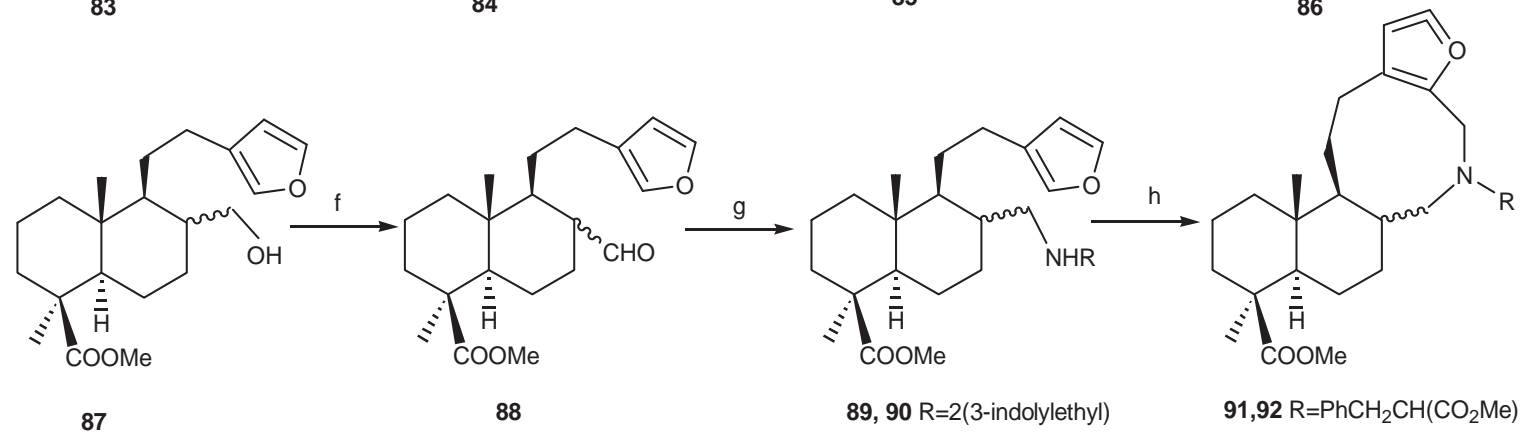

Reagents: a) $\mathrm{MeNH}_{2} / \mathrm{NaBH}_{4}$; b) $\mathrm{CH}_{2} \mathrm{O}$; c) $\mathrm{PCC} / \mathrm{CH}_{2} \mathrm{Cl}_{2}$; d) $\mathrm{MeNH}_{2} / \mathrm{NaBH}_{4}$; e) $\mathrm{CH}_{2} \mathrm{O}$; f) $\mathrm{PCC} / \mathrm{CH}_{2} \mathrm{Cl}_{2}$; g) $\mathrm{MeNH}_{2} / \mathrm{NaBH}_{4} ;$ h) $\mathrm{CH}_{2} \mathrm{O}$.

\section{Scheme 10}

Focusing on the preparation of the new diterpenoids of labdane series that contain a heterocyclic fragment of 10-oxa-3-azatricyclo[5.2.1.01,5]decene (93), the intramolecular [4+2]-cycloaddition reaction of quaternary ammonium salts obtained by quaternization with allyl, methallyl, or propargyl bromides of lambertian acid dialkylaminomethyl derivatives was investigated [36].

Kharitonov Yu.V. et al. [37] report on an interesting approach to the new heterocyclic derivatives of labdanoids that is based on the transformation of 15,16-epoxylabdadiene-15,16-dione (94). The starting compound for this synthesis is readily obtained by oxidative transformations of accessible methyl lambertianate (79).

The oxidation of furan labdanoid (79) with Jones' reagent gave rise to a mixture of the corresponding anhydride (94) and hydroxybutenolides (95) and (96) whose ratio depended on the reaction conditions. By reaction with secondary amines compound (94) gave new terpenyl-containing N-substituted maleimides (97) and (98) (Scheme 11). It is well-known that the reaction of maleic anhydride and its substituted analogs with hydrazines represents an efficient procedure for the preparation of pyridazinediones. The reaction of anhydride (94) with hydrazine hydrate occurred in acetic acid at room temperature and afforded a mixture of 3,6-dioxo-1,2,3,6-tetrahydropyridazine (99) and (N-amino) maleimid (100) (in 47 and 15\% yield). The reaction of anhydride (94) with phenylhydrazine required more stringent condition, since 3-hydroxy-l-phenyl-(2H)-pyridazin-6-one (101) and (N-amino)maleimide (102) could be obtained under boiling the reagent mixture in acetic acid in 22 and $38 \%$ yield, respectively. Thus diterpenoids of new structural type, labdanopyridazinediones, were prepared for the first time. 
<smiles>C=C1CC[C@@H]2[C@@H](CCCC2(C)C)[C@H]1CCc1ccoc1</smiles>

79

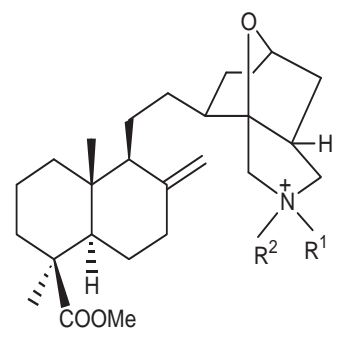

93
94<smiles>[R7]C1C(=O)C=C(CC[C@H]2C(=C)CC[C@]3(C)[C@@H](C)CCC[C@]23C)C1=O</smiles>

- 95a, 95b (R=H)

$\mathrm{b} \longrightarrow 96 \mathrm{a}, 96 \mathrm{~b}(\mathrm{R}=\mathrm{Ac})$
(94)

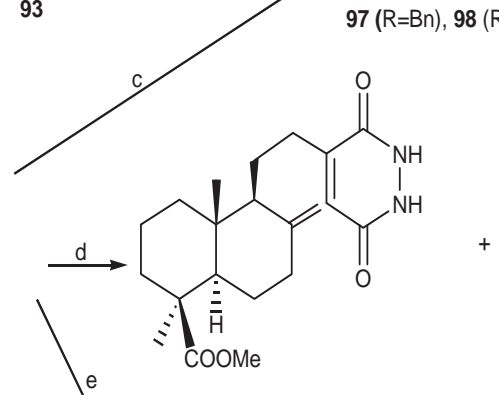

99<smiles>CC(=O)[C@]1(C)CCCC23CCC[C@]1(C)[C@@]2(C)CCc1c(c(O)nn(-c2ccccc2)c1=O)C3</smiles>

101<smiles>C=C1CC[C@H]2[C@@H](C)CCC[C@]2(C)[C@H]1CCC1=CC(=O)N(N)C1=O</smiles>

100

102

Reagents: a) $\mathrm{CrO}_{3}-\mathrm{H}_{2} \mathrm{SO}_{4}$; b) $\mathrm{Ac}_{2} \mathrm{O}-\mathrm{Py}$; c) $\mathrm{RNH}_{2}$; d ) $\mathrm{NH}_{2} \mathrm{NH}_{2}, \mathrm{AcOH}, 20^{\circ} \mathrm{C}$; e) $\mathrm{NH}_{2} \mathrm{NHPh}, \mathrm{AcOH}, 100^{\circ} \mathrm{C}$.

\section{Scheme 11}

The goal of the work described by Kharitonov Yu.V. et al. [38] was to synthesize diterpenoid azlactone from 16-formyllambertianic acid methyl ester (103) and study its reactions with nucleophiles. They found that aldehyde (103) reacts with hippuric acid (104) under standard conditions to give labdanoid oxazol-5(4H)-one (105) in 44\% yield (conversion 56\%) (Scheme 12). Azlactone (105) smoothly reacted with primary amines [such as aniline, benzylamines, and phenylethyl (propyl)amines] and 7-aminoheptanoic acid on heating in benzene to give 59-91\% conversion into $N$-(1-carbamoylvinyl) benzamides (106)-(115). The lowest yield was observed in the reaction with 3,5,6-trimethoxybenzylamine, while the extension of the alkyl chain between the benzene ring and amino group was noted to increase the product yield. For the interaction of compound (105) with secondary amines (piperidine and $N$-methylphenylmethanamine) the prolonged heating was required and the corresponding terpenoid $N$-(carbamoylvinyl) benzamides (113) and (114) were isolated in 73-80\% yield. Treatment of compound (105) with L-proline tert-butyl ester smoothly afforded $83 \%$ of the pyrrolidine-containing labdanoid (115). Azlactone (105) readily reacted with $\alpha$-amino acid (leucine and isoleucine) esters, furnishing in 62-78\% yield the terpenoid $N$-(2-benzoylaminoacryloyl) amino acid esters (116) and (117). Terpenoid oxazol-5(4H)-one (105) undergoes hydrolysis on treatment with a solution of hydrogen chloride in diethyl ether or with $10 \%$ alcoholic alkali, the obtained product being identified as individual $\alpha$-acylamino acid (118) with $Z$ - configuration of the double bond. 
Thus, the condensation of 16-formyllambertianic acid methyl ester with hippuric acid was investigated that gave the corresponding 4,5-dihydrooxazol-5-one derivatives. Their subsequent transformations open exciting synthetic routes to new nitrogen-containing derivatives of the labdane series.

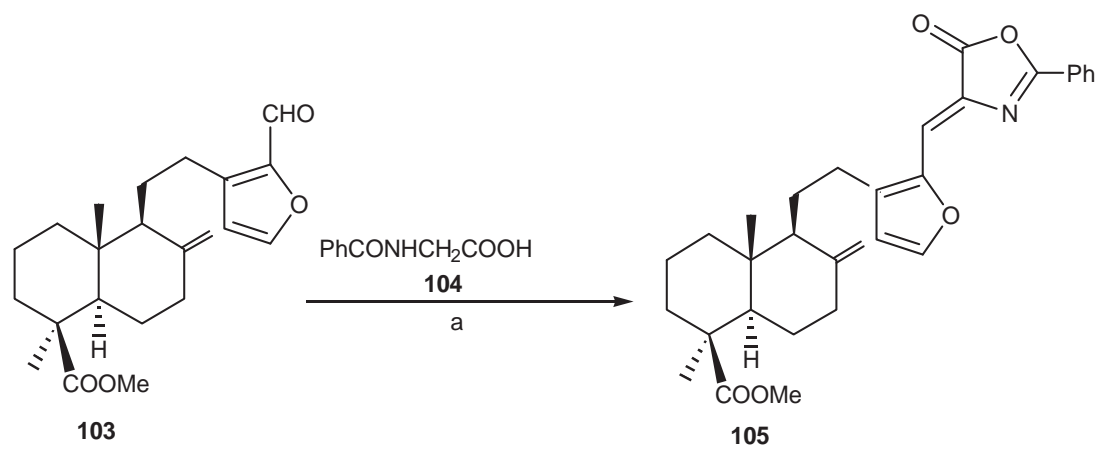

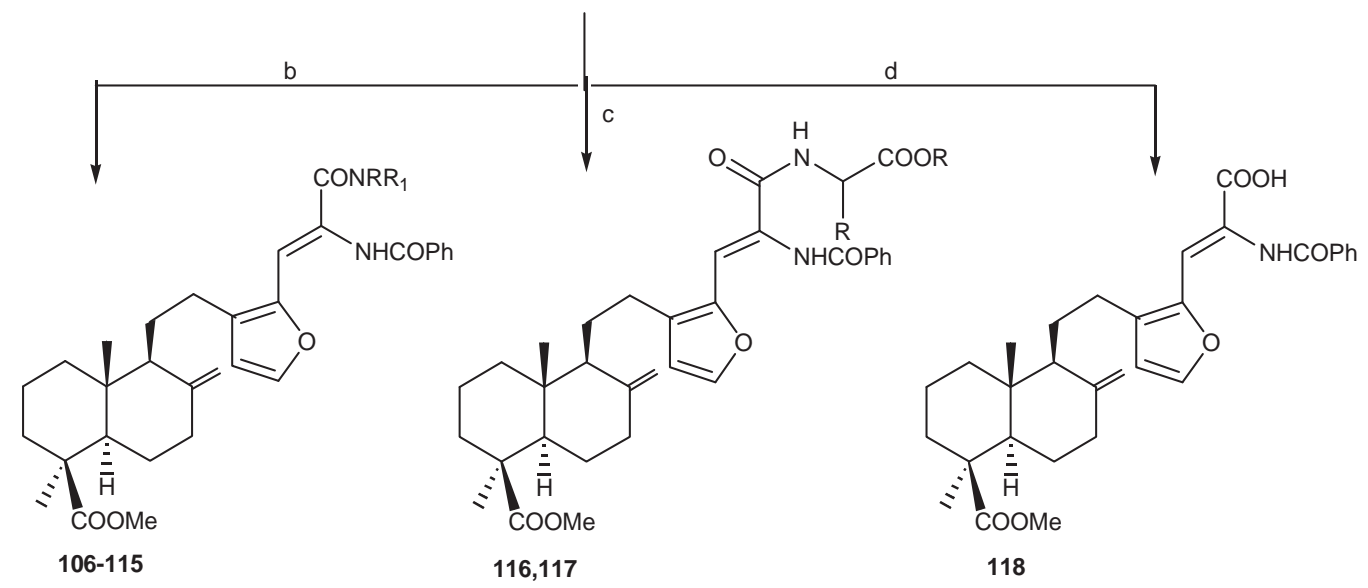

$106-112, \mathrm{R}^{\prime}=\mathrm{H} ; 106, \mathrm{R}=\mathrm{Ph} ; 107, \mathrm{R}=\mathrm{PhCH}_{2} ; 108, \mathrm{R}=4-\mathrm{HOC}_{6} \mathrm{H}_{4}\left(\mathrm{CH}_{2}\right)_{2} ; 109, \mathrm{R}=3,4,5-(\mathrm{MeO})_{3} \mathrm{C}_{6} \mathrm{H}_{2} \mathrm{CH}_{2} ; 110, \mathrm{R}=3,5-(t-\mathrm{Bu}) 2-4-\mathrm{HOC} 6 \mathrm{H}_{2}\left(\mathrm{CH}_{2}\right)_{2} ; 111, \mathrm{R}=$ 3,5- $(t-\mathrm{Bu}) 2-4-\mathrm{HOC}_{6} \mathrm{H}_{2}\left(\mathrm{CH}_{2}\right)_{3} ; 112, \mathrm{R}=\mathrm{HOCO}\left(\mathrm{CH}_{2}\right)_{6} ; 113, \mathrm{R}=\mathrm{PhCH}_{2}, \mathrm{R}^{\prime}=\mathrm{Me} ; 114, \mathrm{RR}^{\prime}=\left(\mathrm{CH}_{2}\right)_{5} ; 115, \mathrm{RR}{ }^{\prime} \mathrm{N}=2$-(tert-butoxycarbonyl)pyrrolidin-1-yl; 116, $\mathrm{R}=\mathrm{MeCH}_{2} \mathrm{CH}(\mathrm{Me}), \mathrm{R}^{\prime}=\mathrm{Me} ; 117, \mathrm{R}=\mathrm{Me}_{2} \mathrm{CHCH}_{2}, \mathrm{R}^{\prime}=t$ - $\mathrm{Bu}$.

Reagents: a) $\mathrm{Ac}_{2} \mathrm{O}, \mathrm{K}_{2} \mathrm{CO}_{3}$; b) $\mathrm{NHRR}^{1}, \mathrm{PhH}, 75^{\circ} \mathrm{C}$; c) $\mathrm{H}_{2} \mathrm{NCHRCOOR}^{1}, \mathrm{PhH}, 75^{\circ} \mathrm{C}$; d) $\mathrm{H}^{+}$.

\section{Scheme 12}

Oxidative methoxylation of 8,17-isopropylidenedioxy derivative of lambertianic acid methyl ester (119) with $N$-chlorobenzenesulfonamide in methanol [39] produced almost quantitatively a mixture of stereomeric 2,5dimethoxydihydrofuran derivatives (120a)-(120d) (Scheme 13). The two cis and two trans stereoisomers were formed in equal amounts, as concluded from the intensities of signals for methoxy protons and 14- $\mathrm{H}, 15-\mathrm{H}$, and $16-\mathrm{H}$ in the ${ }^{1} \mathrm{H}$ NMR spectra. Hydrogenation of compounds (120a)-(120d) over Raney nickel respectively afforded the 2,5-dimethoxytetrahydrofuran derivatives (121a)-(121d), which were in turn subjected to the reaction with methylor ethylamine in acetic acid to give of the corresponding $N$-alkylpyrroles (122) and (123) in 75-84\% yield. As it was noted, the extension of the reaction times result in the formation of diols (124) and (125). The glicols (126)-(128) were synthesized in 51-75\% yield when the 2,5-dimethoxytetrahydrofurans (121a)-(121d) interacted with allylamine, benzylamine and aniline, respectively, on prolonged heating in acetic acid. By periodate oxidation of diols (124) and (125) that was performed in the presence of acetic acid in methanol, we obtained the decahydronaphtho[1,2-g]indoles (129) and (130) in moderate yields (46-51\%) as a result of the cyclization of intermediate 8-oxo-17-norlabdanoids. It should be mentioned that the oxidation of compounds (126)-(128) with sodium periodate under neutral conditions gave the 8-oxo-17-nor derivatives (131)-(133) in good yields (76-83\%). Ketones (131)-(133) were subjected to the intramolecular ring closure furnishing the N-substituted decahydronaphtho[1,2-g]-indoles (134)-(136) in acceptable yields (71-77\%). 


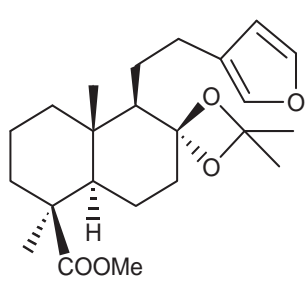

119

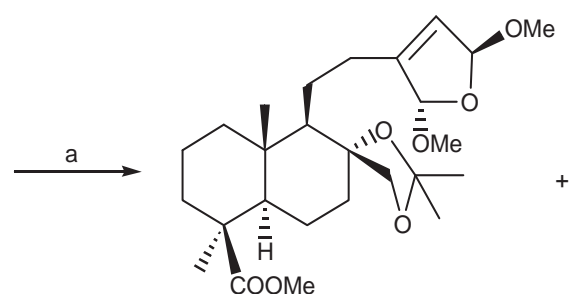

$120 \mathrm{a}$<smiles>CO[C@@H]1C=C(CC[C@H]2[C@H](OC(C)(C)C)CC[C@H]3[C@@H](C)CCC[C@@]32C)[C@@H](OC)O1</smiles>

$120 \mathrm{~b}$<smiles>CO[C@H]1C=C2CC[C@H]3[C@](C)(CCC[C@@]3(C)C(C)=O)[C@@]2(CC(C)(C)O)O1</smiles>

$120 \mathrm{c}$

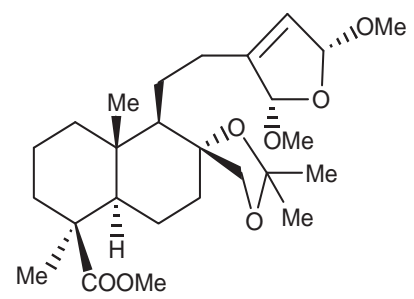

$120 \mathrm{~d}$

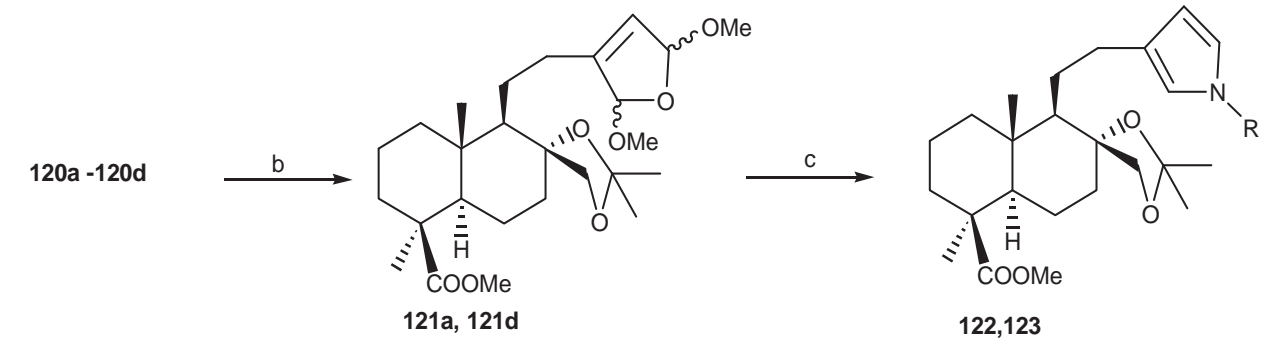

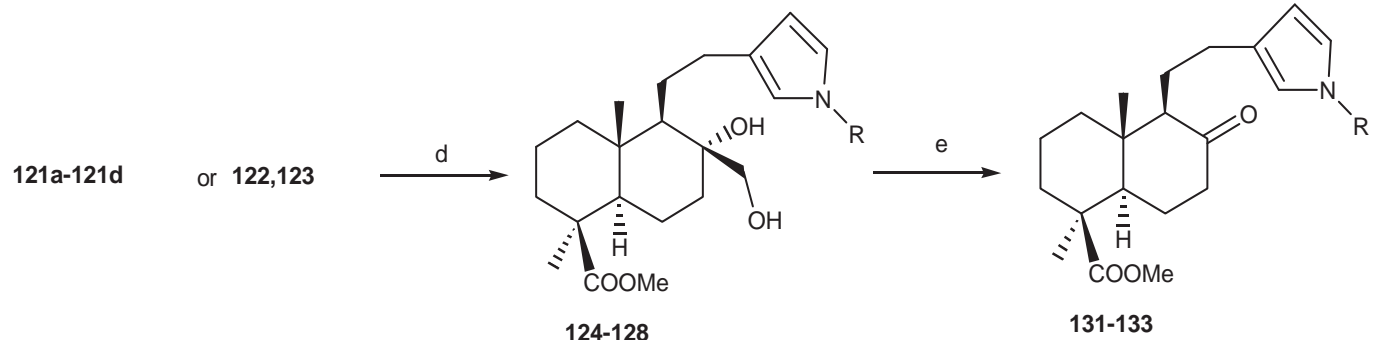<smiles>[R]n1ccc2c1C1=CC[C@]3(C)[C@@H](C)CC[C@](C)(CC)[C@@]3(C)CCC12</smiles>

$129,130,134-136$

122, 124, 129, R = Me; 123, 125, 130, R = Et; 126, 131, 134, R = $\mathrm{PhCH}_{2} ; 127,132,135, \mathrm{R}=\mathrm{CH}_{2}=\mathrm{CHCH}_{2} ; 128,133,136, \mathrm{R}=\mathrm{Ph}$

Reagents: a) $\mathrm{PhSO}_{2} \mathrm{NHCl}, \mathrm{MeOH}$; b) $\mathrm{H}_{2}$ /Raney Ni, $\mathrm{MeOH}$; c) $\mathrm{RNH}_{2}, \mathrm{H}_{2} \mathrm{O}, \mathrm{AcOH}$; d) $\mathrm{RNH}_{2}, \mathrm{H}_{2} \mathrm{O}, \mathrm{AcOH}$; e) $\mathrm{NaIO} 4 \mathrm{MeOH}$; f) $\mathrm{MeOH}, \mathrm{AcOH} ; \mathrm{g}) \mathrm{NaIO}_{4}, \mathrm{H}_{2} \mathrm{O}, \mathrm{MeOH}, \mathrm{AcOH}$.

\section{Scheme 13}

The work described by Kharitonov Yu.V. et al. [40] was intended to the development of procedures for the synthesis of oxatricyclic $\gamma$-lactams with a terpenoid fragment via intramolecular [4+2]-cycloaddition of $N$-furfuryl amides of accessible labdane diterpenoids. Acylation of methyl 16-(benzylaminomethyl)lambertianic acid methyl ester (137) with 2-methylprop-2-enoyl chloride in chloroform in the presence of triethylamine (1.5 eq.) gave the corresponding methacrylic acid amide (138) in 64\% yield. The latter underwent intramolecular cyclization on heating 
in boiling benzene $(8 \mathrm{~h})$. The only exo adducts could be found in the reaction product, as established by analysis of the reaction mixture. The diastereoisomeric methyl $(1 R, 5 S, 7 R)$ - and $(1 S, 5 R, 7 S)-5$-\{2-(3-benzyl-5-methyl-4-oxo-10-oxa-3azatricyclo[5.2.1.01,5]dec-8-en-9-yl)ethyl $\}$-1,4a dimethyl-6-methylidenedecahydronaphthalene-1-carboxylates (139a) and $(139 \mathrm{~b})$ were obtained in a 1:1 ratio (75\% overall yield) (Scheme 14$)$.<smiles>C=C1CC[C@]2(C(C)=O)[C@@H](C)CCC[C@]2(C)[C@H]1CCc1ccoc1</smiles>

79<smiles>C=C1CC[C@]2(C(C)=O)[C@@H](C)CCC[C@]2(C)[C@H]1CCc1ccoc1CN</smiles>

137<smiles>C=C(C)C(=O)N(Cc1ccccc1)Cc1occc1CC[C@H]1C(=C)CC[C@]2(C)[C@H](C)CCC[C@]12C</smiles>

138

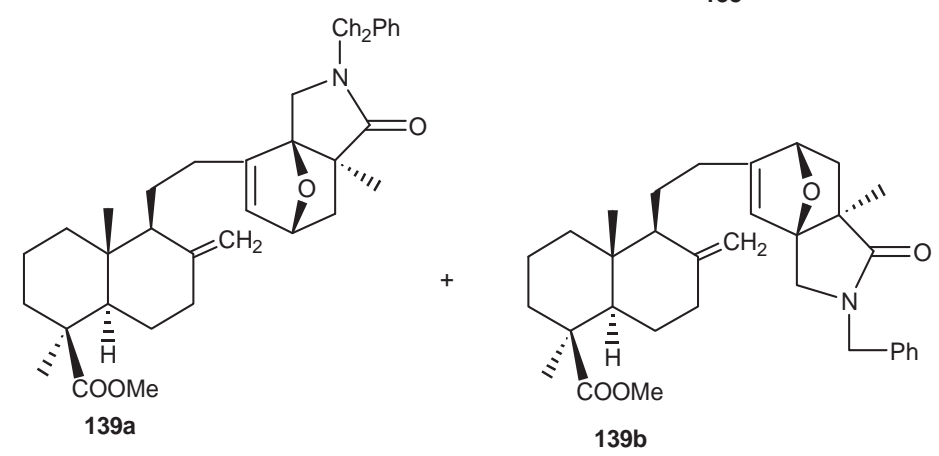

Scheme 14

The smooth isomerisation of lambertianic acid methyl ester (79) into labda-8(9),13(16), 14-triene derivative (140) has been achieved by using $p$-toluenesulfonic acid in benzene ( $89 \%$ yield). The magnesium perchlorate assisted acetylation of diterpenoid (140) with acetic anhydride gave a mixture of 16- and 15-acetyl-substituted furanolabdanoids (141) and (142) at a ratio of 1.6:1 in an overall yield of 68\%. Acetylfuran (141) easily reacted with benzylamine in the presence of sodium borohydride and titanium isopropoxide to produce 16-[1-(benzylamino)ethyl]-substituted furanolabdanoid (143) in $81 \%$ yield as a mixture of $(16 \mathrm{a} R)$ - and $(16 \mathrm{a} S)$-diastereoisomers. The interaction of furfurylamine (143) with 2-methylprop-2-enoyl chloride in chloroform in the presence of triethylamine at $0-20^{\circ} \mathrm{C}$ gave the $86 \%$ conversion of diastereoisomeric $(1 R, 2 S, 5 S, 7 R)$ - and $(1 R, 2 R, 5 S, 7 R)$-2-methyl-10-oxa-3-azatricyclo-[5.2.1.01,5]decenones (144a) and (144b), differing by their configuration at the C-2 chiral center, at a ratio of 1:1. The intermediate methacrylamide (145) was not isolated, but its formation was detected by ${ }^{1} \mathrm{H}$ NMR spectroscopy after $2 \mathrm{~h}$ of mixing the reagents. It has been observed that in the intramolecular cycloaddition the $\alpha$-methyl-substituted amide (141) is more reactive than its analog (138). Under the acylation of amine (143) with maleic anhydride the mixture of diastereoisomeric $(1 R, 2 S, 5 R, 6 R, 7 R)$ - and $(1 R, 2 R, 5 R, 6 R, 7 R)$-adducts (144a) and (144b) has been obtained in equimolar amounts with an overall yield of $86 \%$. 
<smiles>CC(=O)O[C@]1(C)CCC(C)=C(CCc2ccoc2)C1(C)C</smiles>

140<smiles>COCC[C@]1(C)CCC[C@@]2(C)C(CCc3ccoc3C(C)=O)=C(C)CC[C@]12C(C)=O</smiles>

141<smiles>CC(=O)c1cc(CC[C@@H]2C(C)=CC[C@]3(C)[C@@](C)(C(C)=O)CCC[C@]23C)co1</smiles>

142

141<smiles>C=CCCC1=C(C)CC[C@]2(C)[C@@H](C)CCC[C@]12C</smiles>

143

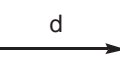<smiles>C=C(C)C(=O)N(Cc1ccccc1)C(C)c1occc1CC[C@H]1C(C)=CC[C@]2(C)[C@@H](C)CCC[C@]12C</smiles>

145<smiles></smiles>

$144 a$

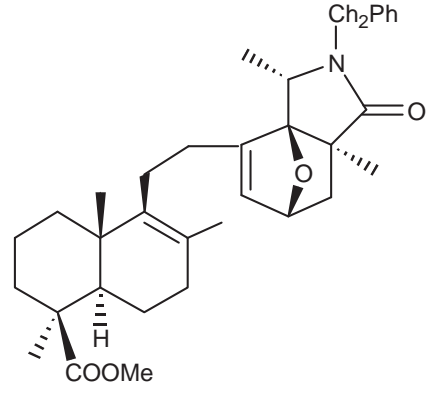

144b

Reagents: a) TsOH, 88\%; b) $\mathrm{Ac}_{2} \mathrm{O}, \mathrm{Mg}\left(\mathrm{ClO}_{4}\right)_{2}$; c) $\mathrm{PhCH}_{2} \mathrm{VH}_{2}, \mathrm{NaBH}_{4}$, (i-PrO) $)_{4} \mathrm{Ti}$; d) $\mathrm{CH}_{2}=\mathrm{C}(\mathrm{Me}) \mathrm{COCl}$

\section{Scheme 15}

The aminomethylation of methyl 16-formyllambertianate (103) with L-methionine methyl ester or L-isoleucine tert-butyl ester provided the amino acid derivatives of the lambertianic acid (146) and (147) in 63 and $76 \%$ yield, respectively (Scheme 16) [41]. The corresponding $N$-furfurylamides (148)-(149) were obtained by the acylation of compounds (146) and (147) with methacryloyl or crotonyl chlorides in chloroform in the presence of triethylamine. Boiling of the amides (148)-(151) in benzene solution resulted in their intramolecular cyclization. The analysis of the reaction mixture showed that the reaction afforded exclusively the exo-adducts, terpenoid 5-methyl-10-oxa-3azatricyclo[5.2.1.01,5]dec-8-en-4-ones as a mixture of $(1 R, 5 S, 7 R)$ - and $(1 S, 5 R, 7 S)$-diastereomers $(152 \mathrm{a}),(152 \mathrm{~b})$, $(154 \mathrm{a})$ and $(154 \mathrm{~b})$ or 6-methyl-10-oxa-3-azatricyclo-[5.2.1.01,5]dec-8-en-4-ones as a mixture of $(1 R, 5 S, 6 R, 7 R)$ - and $(1 S, 5 R, 6 S, 7 S)$-diastereomers (153a), (153b), (155a) and (155b) (85-89\% yields). 


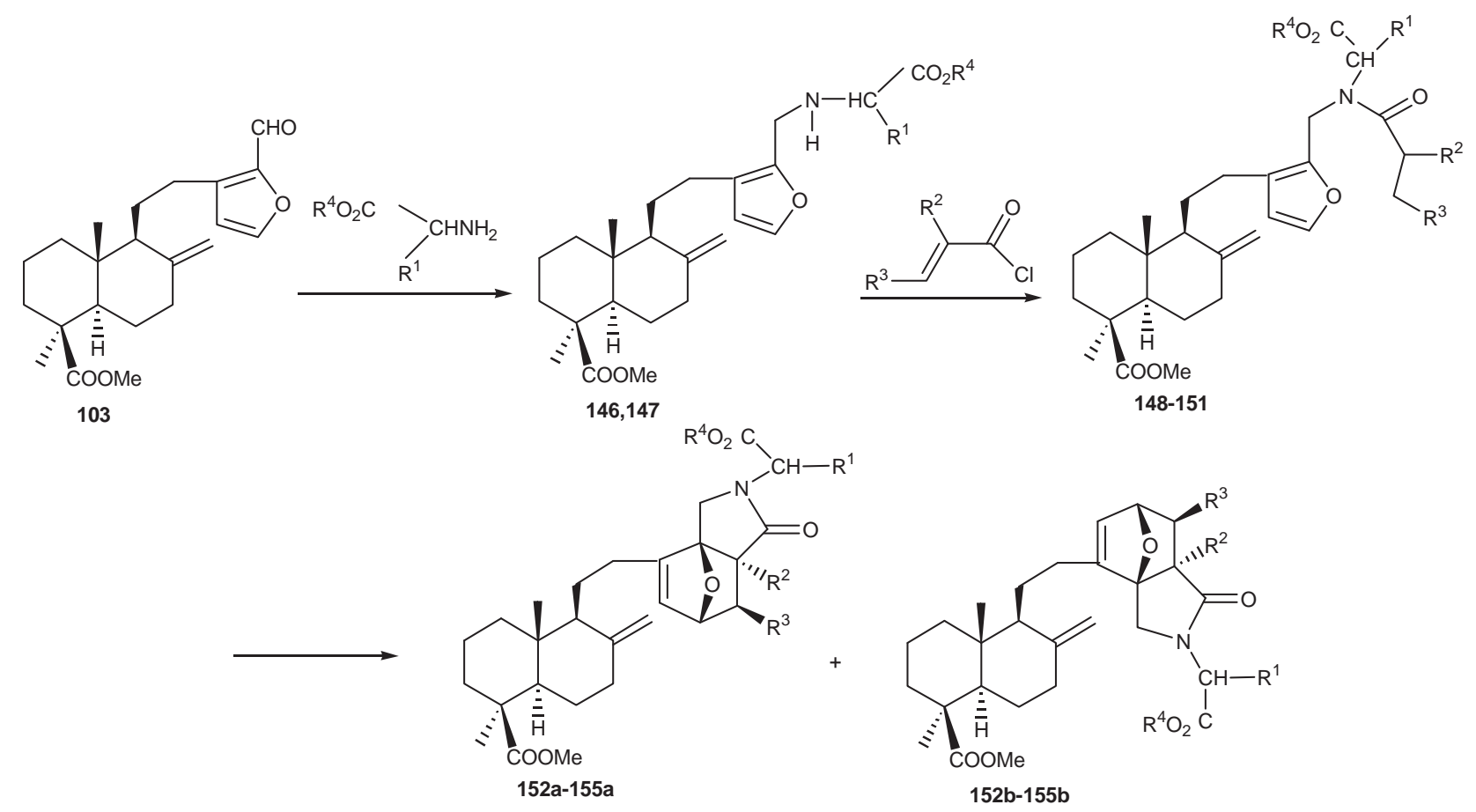

$\mathrm{R}^{1}=\left(\mathrm{CH}_{2}\right)_{2} \mathrm{SCH}_{3}, \mathrm{R}^{4}=\mathrm{CH}_{3}(146) ; \mathrm{R}^{1}=\mathrm{CH}\left(\mathrm{CH}_{3}\right) \mathrm{CH}_{2} \mathrm{CH}_{3}, \mathrm{R}^{4}=t-\mathrm{Bu}(147) ; \mathrm{R}^{1}=\left(\mathrm{CH}_{2}\right)_{2} \mathrm{SCH}_{3}, \mathrm{R}^{2}=\mathrm{CH}_{3}, \mathrm{R}^{3}=\mathrm{H}, \mathrm{R}^{4}=\mathrm{CH}_{3}((148),(152 \mathrm{a}),(152 \mathrm{~b})) ; \mathrm{R}^{1}=\left(\mathrm{CH}_{2}\right) \mathrm{SCH}_{3}, \mathrm{R}^{2}=$ $\mathrm{H}, \mathrm{R}^{3}=\mathrm{R}^{4}=\mathrm{CH}_{3}((149),(153 \mathrm{a}),(153 \mathrm{~b}))$;

$\mathrm{R}^{1}=\mathrm{CH}\left(\mathrm{CH}_{3}\right) \mathrm{CH}_{2} \mathrm{CH}_{3}, \mathrm{R}^{2}=\mathrm{CH}_{3}, \mathrm{R}^{3}=\mathrm{H}, \mathrm{R}^{4}=\mathrm{C}\left(\mathrm{CH}_{3}\right)_{3}((150),(154 \mathrm{a}),(154 \mathrm{~b})) ; \mathrm{R}^{1}=\mathrm{CH}\left(\mathrm{CH}_{3}\right) \mathrm{CH}_{2} \mathrm{CH}_{3}, \mathrm{R}^{2}=\mathrm{H}, \mathrm{R}^{3}=\mathrm{CH}_{3}, \mathrm{R}^{4}=\mathrm{C}\left(\mathrm{CH}_{3}\right)_{3}((151),(154 \mathrm{a}),(154 \mathrm{~b}))$.

\section{Scheme 16}

For further studies of the effect of substituents in the dienophilic fragment of terpenoid N-furfurylamides, the synthesis and properties of cyclic N-alkenyl derivatives of labdanoids have been considered. Consequently it was found that methyl 16-formyllambertianate (103) readily reacted with cystamine in benzene at reflux in the presence of triethylamine generating the methyl-16-(thiazolidin-2-yl)lambertianate (156) (Scheme 17).

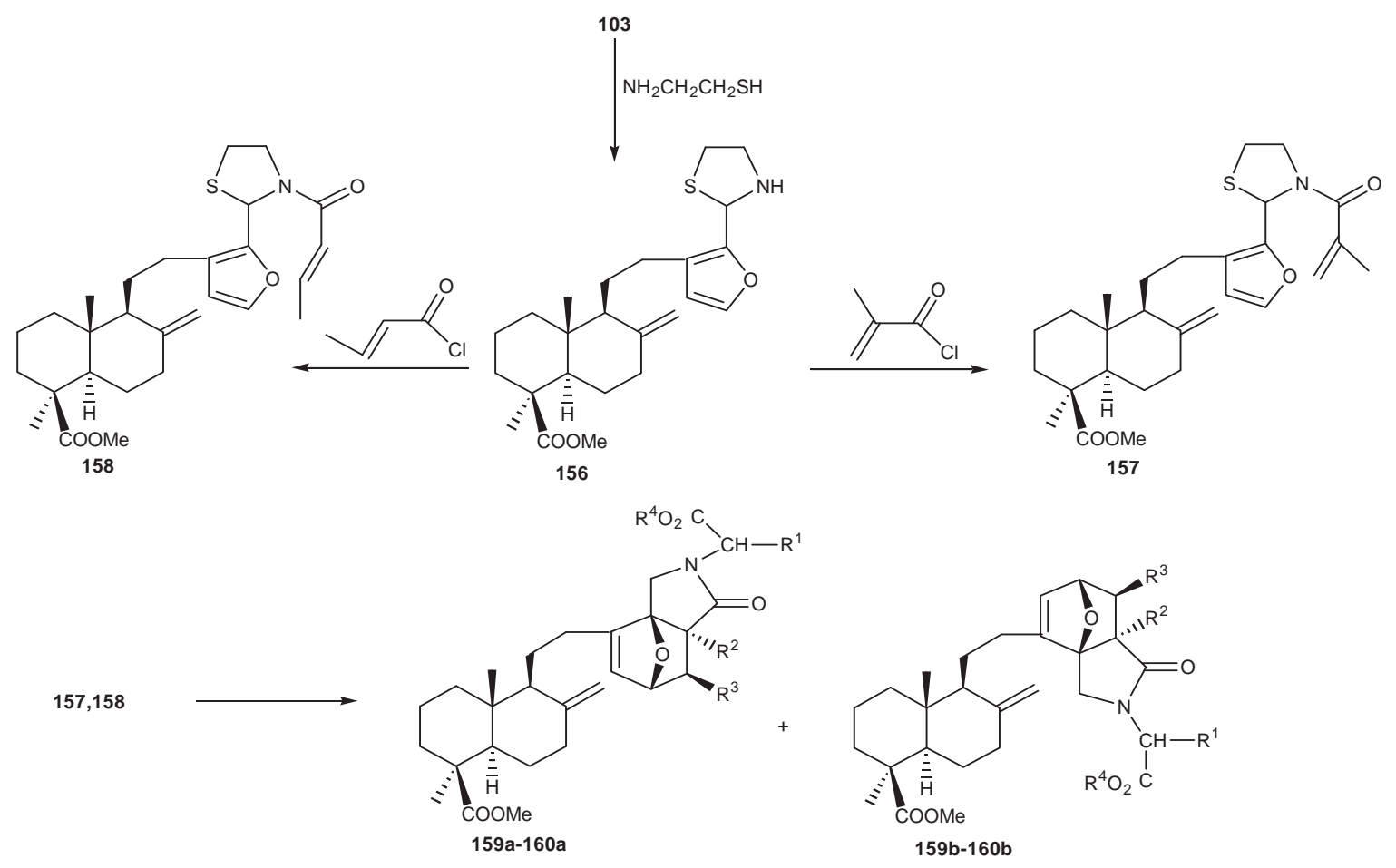

Scheme 17 
The acylation of compound (156) with methacryloyl or crotonyl chlorides and assisted by triethylamine in chloroform led to the formation of N-methylacryloyl- (157) or N-crotonyl-2-furylthiazolidines (158) in good yields ( 75 and $82 \%$, respectively). The intramolecular cyclization of compounds (157) and (158) was achieved by $10 \mathrm{~h}$ reflux in benzene and resulted in the corresponding terpenoid derivatives of hexahydrothiazolo[2,3-a]isoindolinone (159a), (159b), (160a) and (160b) in 92-96\% yields.

The heterocyclic system of dihydroisoindol-1-one constitutes a structural moiety of a number of polycyclic alkaloids, known for the variety of the exhibited biological activities. This motivated the ulterior diggings aimed to the synthesis of functionalized dihydroisoindolones that contain a labdanoid fragment [42]. As starting compound for the synthesis of terpenoid dihydroisoindol-1-ones the accessible furan diterpenoid, phlomisoic acid methyl ester (161) has been selected. Vilsmeier-Haak formylation of phlomisoic acid methyl ester (161) provided a mixture of three compounds, 16-formyllabdatrienoate (162), 15-formyllabdatrienoate (163) and 2-formylmarginatafuran (164) in 79, 8 and $2 \%$ yield, respectively (Scheme 18 ).

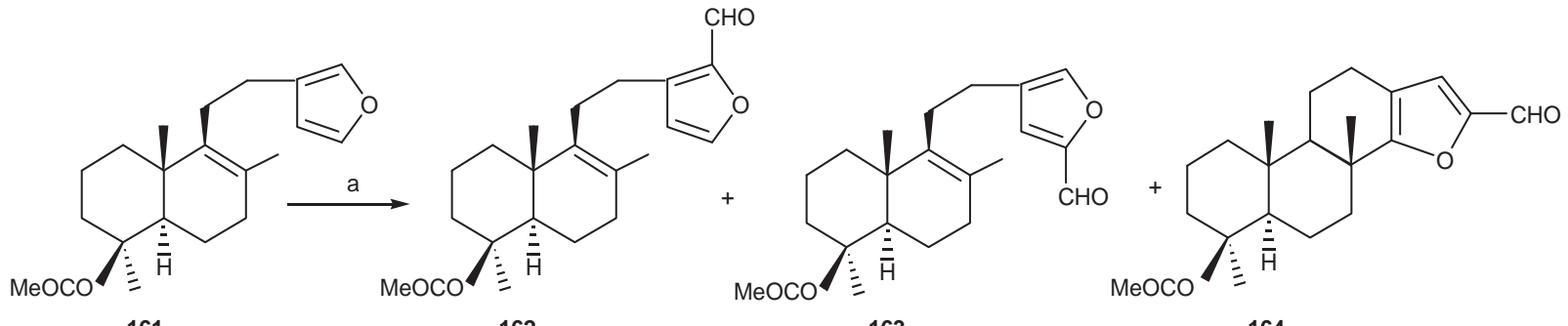

161

162

163

164<smiles>CO[C@H]1CCC[C@]2(C)C(CCc3ccoc3CNc3ccccc3)=C(C)CC[C@H]12</smiles>

165<smiles>[R]C(NCc1occc1CC[C@H]1C(C)=CC[C@@H]2[C@@H](OC(C)=O)CCC[C@]21C)C(C)=O</smiles>

166-168

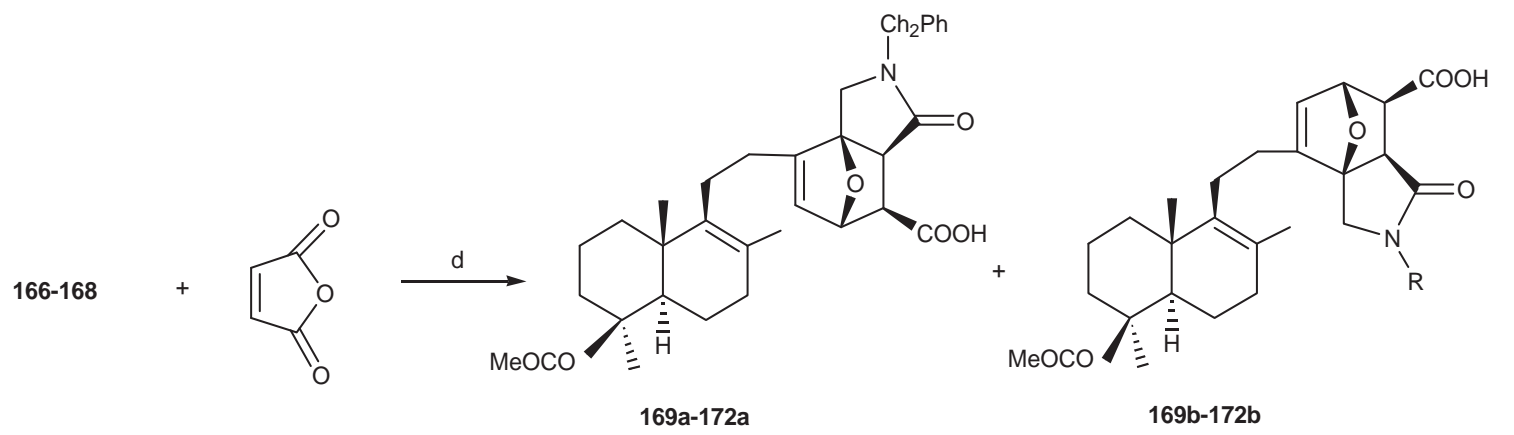

$166 \mathrm{R}=\mathrm{Me}, 167 \mathrm{R}=\mathrm{Me}_{2} \mathrm{CH}, 168 \mathrm{R}=\mathrm{MeS}\left(\mathrm{CH}_{2}\right)_{2} ; 169 \mathrm{R}=\mathrm{PhCH}_{2} ; 170 \mathrm{R}=\mathrm{MeCH}\left(\mathrm{CO}_{2} \mathrm{Me}\right) ; 171 \mathrm{R}=\mathrm{Me}_{2} \mathrm{CHCH}\left(\mathrm{CO}_{2} \mathrm{Me}\right) ; 171 \mathrm{R}=\mathrm{MeS}(\mathrm{CH})_{2} \mathrm{CH}\left(\mathrm{CO} \mathrm{Me}_{2}\right)$.

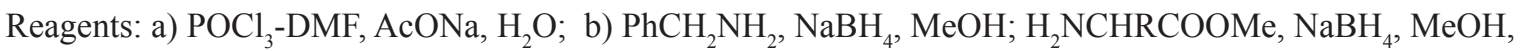
c) $\mathrm{H}_{2} \mathrm{NCHRCOOMe}, \mathrm{NaBH}_{4}, \mathrm{MeOH}$; d) $\mathrm{PhH}, 20^{\circ} \mathrm{C}$.

\section{Scheme 18}

Reductive amination of methyl 16-formyllabda-8(9),13(16), 14-trienoate (162) with benzylamine, or with D,L- $\alpha$ amino acid methyl esters, in the presence of sodium tetrahydridoborate gave the corresponding labdanoid furfurylamines (165) or furfurylamino acids (164)-(168) in 76-90\% yield (Scheme18). In order to obtain the furfurylacrylamides the acylation of compounds (165)-(168) with maleic anhydride and crotonoyl chloride has been examined. The reaction of 16-aminomethyl labdanoids (165)-(168) with maleic anhydride occurred under mild conditions in benzene, at $20^{\circ} \mathrm{C}$ and 
involved the intermediate formation of $N$-furfurylmaleamic acids that were converted into the $N$-substituted 4-oxo-1,7epoxyhexahydroisoindole-6-carboxylic acids (169)-(172) in 72-96\% yield via the exo-transition state.

\section{Synthesis of nitrogen-containing compounds of the enantiomeric series from andrographolide and some of its rearranged derivatives}

Andrographolide (173) - the major constituent of the Indian medicinal plant Andrographis paniculata, has been lately reported to be conveniently involved in the development of an efficient semi-synthetic procedure for the preparation of structurally diverse labdanes [43]. The proposed method started with the selective oxidative degradation of the C-12(13) olefin bond of the discussed compound (173) into the key-intermediate (174), which served as a precious chiral intermediate (Scheme 19).<smiles>C=C1CC[C@H]2[C@@H](CC[C@@H](O)[C@@H](C)[C@@H]2CO)C1C/C=C1/NC(=S)SC1=O</smiles>

175<smiles>C=C1CC[C@]2(C)[C@H](C)[C@@H](O)CC[C@@]2(C)[C@H]1C/C=C1/NC(=O)SC1=O</smiles><smiles>C=C1CC[C@]2(C)[C@H](C)[C@@H](O)CC[C@@H]2[C@H]1C/C=C1\C(=O)Nc2ccccc21</smiles><smiles>C=C1CC[C@H]2[C@@H](C)[C@H](O)CC[C@]2(C)[C@H]1C/C=C1/C(=O)OC[C@H]1O</smiles>
173 174<smiles>C=C1CC[C@]2(C)[C@@H](CC[C@@H]3OC(C)(C)OC[C@H]32)C1CCc1cnc(N)[nH]c1=O</smiles><smiles>C=C1CC[C@H]2[C@@H](OC(C)(C)C)C[C@H](Cc3cc(=O)[nH]c(N)n3)[C@@]2(C)CC1</smiles>

178

Reagents: a) 1. 2,2-dimethoxypropane/PPTS/benzene/reflux, 95\%; 2. Ac O/TEA/DCM/rt, 95\%; 3. DMAP/ $\mathrm{DCM} / \mathrm{rt}, 80 \%$; 4. aq $\mathrm{KMnO}_{4} / \mathrm{THF}$, rt, $62 \%$; b) 1. rhodanine/thiazolidinedione/oxindole, b-alanine/benzene/reflux; 2. $\mathrm{AcOH} / \mathrm{H}_{2} \mathrm{O}$ (7:3), c) 1. $\mathrm{BrCH}_{2} \mathrm{CO}_{2} \mathrm{Et} / \mathrm{Zn} /$ benzene/reflux, (70\%); 2. PDC, DCM/rt, (90\%); 3. guanidinium chloride/ $/ \mathrm{NaOMe} / \mathrm{MeOH} /$ reflux, $(60 \%)$; d) 1. ethyl acetoacetate/TiCl $/$ /py, (70\%); 2. $\mathrm{NaBH}_{4} / \mathrm{MeOH}(95 \%) ; 3$. $\mathrm{PDC} / \mathrm{DCM}$, (95\%); 4. guanidine hydrochloride/ $\mathrm{NaOMe} / \mathrm{MeOH} / \mathrm{reflux}(60 \%)$.

\section{Scheme 19}


The latter was converted into a number of labdane diterpenes by utilizing its aldehyde functionality. Knoevenagel condensation of compound (174) with rhodanine, thiazolidinedione and oxindole, followed by the elimination of the C-3,19-isopropylidene protection, furnished compounds (175), (176) and (177). Compound (178) containing the aminopyrimidone moiety in the side chain was synthesized by Reformatsky reaction of (174) with ethyl bromoacetate, followed by pyridinium dichromate oxidation and condensation with guanidine. The corresponding homologue (179) was prepared as shown in scheme $19(\mathrm{~d})$.

An effective synthesis of (+)-agelasine C (180) has been achieved from ent-halimic acid methyl ester (182) [44]. The structure and absolute configuration of the natural product (-)-agelasine C (180) was established.

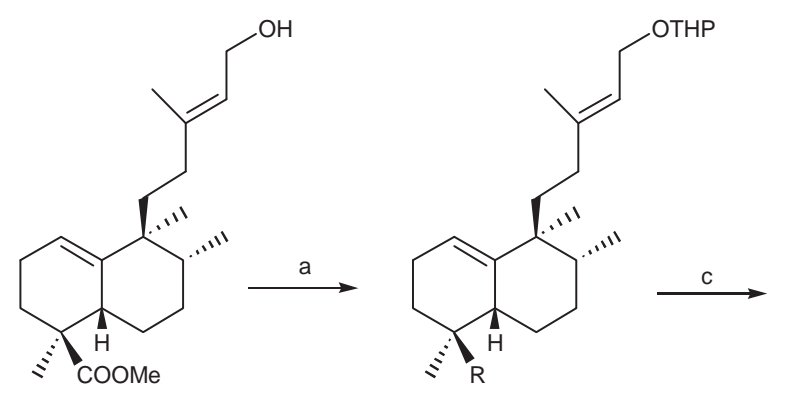

182

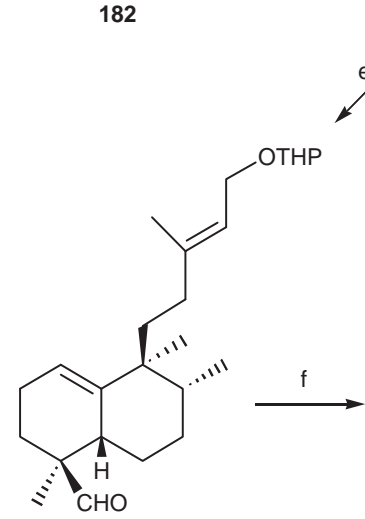

187

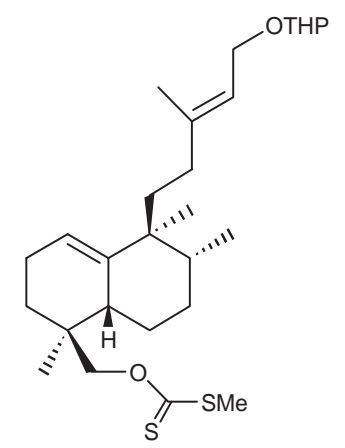

186
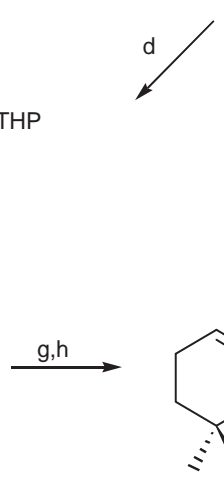

188<smiles>C/C(=C\CBr)CC[C@]1(C)C2=CCCC(C)(C)[C@H]2CC[C@@H]1C</smiles>

183

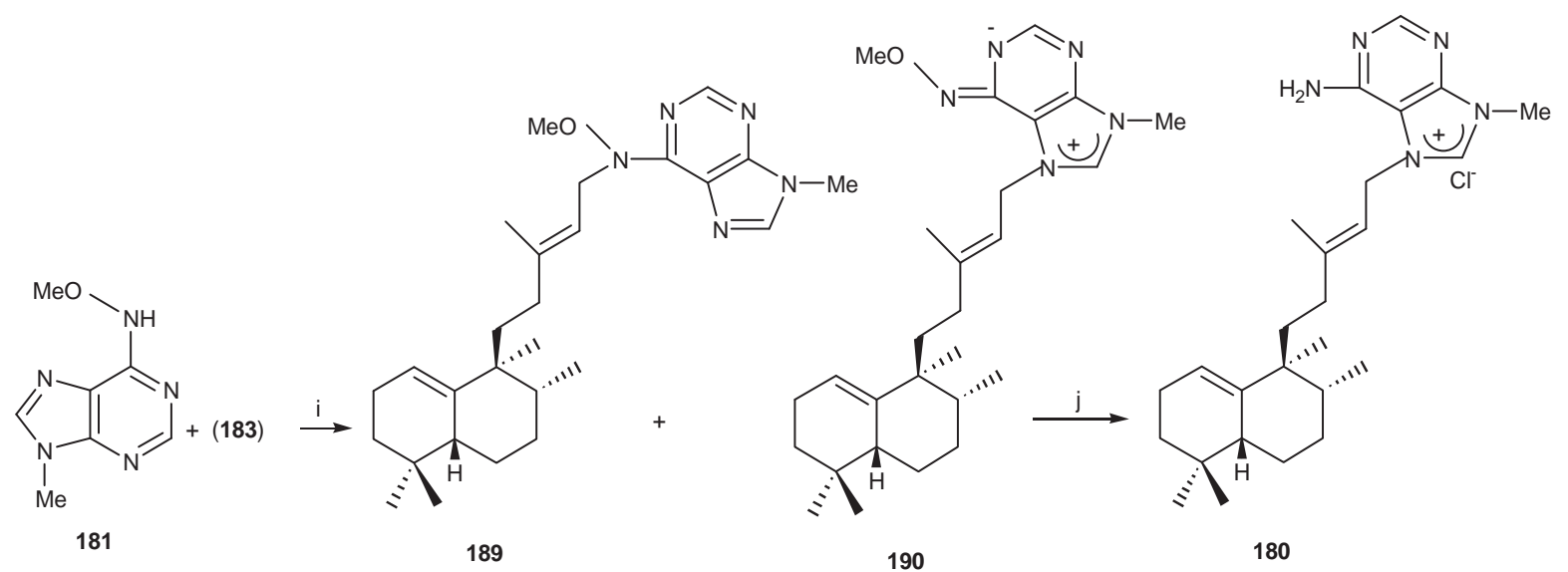

Reagents: a) DHP, p-TsOH, $\mathrm{C}_{6} \mathrm{H}_{6}, 15 \mathrm{~min}, \mathrm{rt},(98 \%)$; b) LAH, Et ${ }_{2} \mathrm{O}, 8^{\circ} \mathrm{C}$ and then rt, $4 \mathrm{~h},(99 \%)$; c) nBuLi, THF, (98\%); d) nBu $\mathrm{SnH}$, AIBN, toluene, $20 \mathrm{~min}$, (31\%); e) TPAP, NMO, DCM, Ar, 45 min, (94\%); f) diethylene glycol, $\left.\mathrm{NH}_{2}-\mathrm{NH}_{2} \mathrm{H}_{2} \mathrm{O}, \mathrm{KOH},(81 \%) ; \mathrm{g}\right) \mathrm{p}-\mathrm{TsOH}, \mathrm{MeOH}, 30 \mathrm{~min},(81 \%)$; h) $\left.\mathrm{CBr}_{4}, \mathrm{PPh}_{3}, \mathrm{DCM}, 3 \mathrm{~h},(76 \%) ; \mathrm{i}\right)$ DMA j) $\mathrm{Zn}, \mathrm{MeOH}, \mathrm{H}_{2} \mathrm{O}, \mathrm{AcOH}$, argon.

\section{Scheme 20}

The synthesis of target-compound (180) has been run in a convergent way, considering its purine fragment and the diterpenic part. The purinic fragment (181) was built following the methodology of Fujii [45] from adenine. The 
second part of the synthesis comprised the transformation of enthalimic acid methyl ester (182) into the bromoderivative (183). This conversion required the reduction of the methoxycarbonyl group at C-18 to a methyl group, as well as the substitution of the alcohol function in $\mathrm{C}-15$ with bromine. For the aforementioned reduction at C-18 the necessity of suitable protection at C-15 arose and was solved via the corresponding tetrahydropyrane derivative (Scheme 20). The reaction of methyl ester (182) with 3,4-dihydro-2H-pyran in $p$-TsOH produced compound (184) that by reduction with lithium aluminium hydride lead to the hydroxyderivative (185). The interaction of the latter with carbon disulphide was followed by the treatment with methyl iodide in alkaline media, which led to the xantogenate (186). It was consequently reducted with tributyltin hydride in the presence of azobisisobutyl nitrile giving the reduction product (188) in a modest yield. The outcome of the reductive conversion could be ameliorated when the Huang-Minlon methodology has been employed upon the aldehyde (187), in turn obtained by oxidation of compound (185) with tetra- $n$-propylammonium perruthenate. Deprotection of the primary hydroxy group, followed by the treatment of the hydroxyderivative with $\mathrm{CBr}_{4}$ in the presence of thriphenylphosphine afforded the required bromoderivative (183). Once the two basic fragments have been obtained, the synthesis was continued with the alkylation of methoxyadenine (181) by the bromoderivative (183). It gave the mixture of two isomers: compound (199) corresponding to the N in C-6 alkylation and required (190). The latter was finally reduced with $\mathrm{Zn}$ in acetic acid giving the target-compound (180).

\section{Conclusion}

The above-presented data demonstrate that lately the vast series of known natural terpenoids has been intensely supplemented by the nitrogen-containing metabolites of plant, microbial and animal origin. The unique structure of many so-called mixed metabolites, whose molecules include nitrogen, and their important biological properties make them attractive targets of the total synthesis. On the other hand, they can serve as plausible models for designing the molecules with useful functions.

Thus, the scientific interest remains opened to the exploration of new exciting facets of nitrogen-containing terpenoids.

\section{References}

[1]. Jansen, B. J. M.; de Groot, A. Nat. Prod. Rep., 2004, 21, (4), 449-477.

[2]. Connolly, I. D.; Hill, R. A. Dictionary of Terpenoids, London: Chapman and Hall, 1991, vol. 2, pp. $677-809$.

[3]. Grant, P. K.; Prasad, J. S.; Rowan, D. D. Aust. J. Chem., 1983, 36, (6), 1197-1202.

[4]. Schenk, H. L.; Gutmann, H.; Jeger, O.; Ruzicka, L. Helv. Chim. Acta, 1954, 37, (2), 543-546.

[5]. Fleming, L.; Woodward, R. B. J. Chem. Soc., Perkin Trans. 1, 1973, 1653-1657.

[6]. Urones, J. G.; Diez, D.; Gomez, P. M.; Marcos, I. S.; Basabe, P.; Moro, R. F. Nat. Prod. Lett., 1998, 11, (2), 145152.

[7]. Urones, J. G.; Marcos, I. S.; Perez, B. O.; Diez, D.; Ligthow, A. M.; Gomez, P. M.; Basabe, P.;. Garrido, N. M. Tetrahredron, 1994, 50, (37), 10995-11012.

[8]. Cortes, M.; Lopez J.; Diaz, E. Nat. Prod. Lett., 1993, 2, (1), 37-40.

[9]. Hayashi, T.; Yamamoto, A.; Ito, Y. Tetrahedron Lett., 1988, 29, (1), 99-102.

[10]. Ardabllchi, N.; Fitton, A. O.; Frost, J. R.; Oppong-Boachie, F. K.; Hadi, A. H.; Sharif, A. M. J. Chem. Soc., Perkin Trans. 1, 1979, 539-543.

[11]. Kunieda, T.; Ishizuka, T.; Higuchi, T.; Hirobe, M. J. Org. Chem., 1988, 53, (14), 3381-3383.

[12]. Barrero, A. F.; Alvarez-Manzaneda, E. J.; Chahboun, R.; Gonzalez Diaz, C. Synlett, 2000, (11), $1561-1564$.

[13]. Barrero, A. F.; Alvarez-Manzaneda, E. J.; Altarejos, J.; Salido, S.; Ramos, J. M.; Simmonds, M. S. J.; Blaney, W. M. Tetrahedron, 1995, 51, (27), 7435-7450.

[14]. Heathcock C. H.; Buse C. T.; Kleschick W. A.; Pirrung M. C.; Sohn J. E.; Lampe J. J. J. Org. Chem., 1980, 45, (6), 1066-1081.

[15]. Kuchkova, K. I.; Arycu, A. N.; Vlad, P. F. Chem. Nat. Comp., 2009, 45, (3), 367-370.

[16]. Kuchkova, K. I.; Arycu, A. N.; Dragalin, I. P.; Vlad, P. F. Khim. Prir. Soedin., 2005, (2), 152-155 [Chem. Nat. Comp., 2005, 41, (2), 190-193 (Engl. Transl.)]

[17]. Liu, P. S. J. Org. Chem., 1987, 52, (21), 4717-4721.

[18]. Nystrom, R. F. J. Am. Chem. Soc., 1955, 77, (9), 2544-2545.

[19]. Ipaktschi, J. Chem. Ber., 1984, 117, (2), 856-858.

[20]. Rausser, R.; Weber, L.;. Hershberg, E. B.; Oliveto, E. P. J. Org. Chem., 1966, 31, (5), 1342-1346.

[21]. Hilgetag, G.; Martin, A., Weygand-Hilgetag Preparative Organic Chemistry, Wiley-Interscience, Chichester, Engl., 1979, pp. 520.

[22]. Kim, J. N; Chung, K. H.; Ryu, E. K. Synth. Commun., 1990, 20, (18), 2785-2788. 
[23]. Sosnovsky, G.; Krogh, J. K. Synthesis, 1978, (9), 703-704.

[24]. Boruah, M.; Konwar, D. J. Org. Chem., 2002, 67, (20), 7138-7139.

[25]. Ganboa, I.; Palomo, C. Synth. Commun., 1983, 13, (3), 219-224.

[26]. Saednya, A. Synthesis, 1982, (3), 190-191.

[27]. Capdevielle, P.; Lavingne, A.; Maumy, M. Synthesis, 1989, (6), 451-452.

[28]. Frejd, T.; Klingstedt, T. Synthesis, 1987, (1), 40-42.

[29]. Kuchkova, K. I.; Arycu, A. N.; Vlad, P. F.; Deleanu, K.; Nikolescu, A. Chem. Nat. Comp., 2010, 46, (4), 539544.

[30]. Kuchkova, K. I.; Chumakov, Yu. M.; Simonov, Yu. A.; Bocelli, G.; Panasenko, A. A., Vlad, P. F. Synthesis, 1997, (9), 1045-1049.

[31]. Kuchkova, K. I.; Arycu, A. N.; Barba, A.N.; Vlad, P. F. Chem. Nat. Comp., 2011, 46, (2), $205-210$.

[32]. Kuzuya, K.; Mori, N.; Watanabe, H. Org. Lett., 2010, 12, (21), 4709-4711.

[33]. Chernov, S. V., Shul'ts, E. E., Shakirov, M. M., Tolstikov, G. A. Russ. J. Org. Chem., 2002, 38, (5), $703-709$.

[34]. Kharitonov, Yu. V.; Shul'ts, E. E.; Shakirov, M. M.; Tolstikov, G. A. Russ. J. Org. Chem., 2003, 39 (1), $57-74$.

[35]. Chernov, S. V.; Shul'ts, E. E.; Shakirov, M. M.; Bagryanskaia, I. Yu.;. Gatilov, Yu. V.; Tolstikov, G. A. Russ. J. Org. Chem., 2005, 41, (4), 547-556.

[36]. Kharitonov, Yu. V.; Shul’ts, E. E.; Shakirov, M. M.; Tolstikov, G. A. Russ. J. Org. Chem., 2005, 41, (8), 11451157.

[37]. Kharitonov, Yu. V.; Shul'ts, E. E.; Shakirov, M. M.; Tolstikov, G. A. Russ. J. Org. Chem., 2006, 42, (5), 725735.

[38]. Kharitonov, Yu. V.; Shul'ts, E. E.; Shakirov, M. M.; Tolstikov, G. A. Russ. J. Org. Chem., 2007, 43, (6), 839851 .

[39]. Chernov, S. V.; Shul’ts, E. E.; Shakirov, M. M.; Tolstikov, G. A. Russ. J. Org. Chem., 2008, 44, (1), 67-75.

[40]. Kharitonov, Yu. V.; Shul'ts, E. E.; Shakirov, M. M.; Tolstikov, G. A. Russ. J. Org. Chem., 2008, 44, (4), 521528.

[41]. Kharitonov, Yu. V.; Shul’ts, E. E.; Shakirov, M. M.; Tolstikov, G. A. Russ. J. Org. Chem., 2009, 45, (5), 637649.

[42]. Mironov, M. E.; Kharitonov, Yu. V.; Shul’ts, E. E.; Shakirov, M. M.; Gatilov, Yu. V.; Tolstikov, G. A. Russ. J. Org. Chem., 2010, 46, (12), 1869-1882.

[43]. Nanduri, S.; Nyavanandi, V. K.; Sanjeeva, S.; Thunuguntla, R.; Velisoju, M.; Kasu, S.; Rajagopal, S.; Kumar, R. A.; Rajagopalan, R.; Iqbal, J. Tetrahedron Lett., 2004, 45, (25), 4883-4886.

[44]. Marcos, I. S.; Garcia, N.; Sexmero, M. J.; Basabe, P.; Diez, D.; Urones, J. G. Tetrahedron, 2005, 61, (49), 1167211676.

[45]. Fujii, T.; Itaya, T. Tetrahedron, 1971, 27, (2), 351-360. 